\title{
Preliminary Data on the Mechanisms and Kinetics of the Formation of Petroleum in Sediments. Computer Simulation of a Reaction Flowsheet
}

\author{
B. Tissot $^{1}$ \\ 1 Institut français du pétrole, 1 et 4, avenue de Bois-Préau, 92852 Rueil-Malmaison Cedex - France
}

\begin{abstract}
Résumé - Premières données sur les mécanismes et la cinétique de la formation du pétrole dans les sédiments. Simulation d'un schéma réactionnel sur ordinateur - Des travaux récents ont permis de suivre la formation des composés du pétrole dans les sédiments en fonction de l'enfouissement sur quelques cas géologiques: Toarcien du Bassin de Paris, Mio-Pliocène de Californie. Ces observations permettent de déterminer, pour la formation étudiée, les zones favorables où la matière organique a produit du pétrole.

Pour que ces résultats puissent être généralisés à d'autres formations et d'autres bassins, on a tenté de déduire des observations un schéma réactionnel synthétique, et d'écrire la cinétique correspondant à ce schéma. La simulation sur ordinateur de l'évolution de ce schéma réactionnel permet de calculer les quantités de pétrole formées à partir d'un gramme de matière organique primitive en tout point d'un bassin. Les données nécessaires sont une reconstitution géologique de l'histoire de l'enfouissement et un ensemble de constantes représentant la nature de la matière organique primitive.

Dans le cas du Toarcien du Bassin de Paris, les résultats montrent un excellent accord entre les valeurs ainsi calculées et celles effectivement observées.

On accède également au problème de l'époque et de la vitesse de formation du pétrole pour les comparer avec l'âge des mouvements structuraux qui déterminent la formation des pièges.
\end{abstract}

Abstract - Preliminary Data on the Mechanisms and Kinetics of the Formation of Petroleum in Sediments. Computer Simulation of a Reaction Flowsheet - Recent studies investigated the formation of oil compounds in sediments, as a function of burial depth, in some geological settings of the Toarcian in the Paris Basin and the Mio-Pliocene in California. In the formations examined, these observations served to identify favorable zones where oil was generated by organic matter.

To extend these results to other formations and other basins, an attempt was made to fit them into a synthetic reaction flowsheet and to determine the kinetics corresponding to this flowsheet. The computer simulation of the way in which the reaction flowsheet evolves helps to calculate the amount of oil formed from one gramme of original organic matter, at any point of a basin. The necessary data are the geological reconstruction of the burial history and a set of constants representing the type of original organic matter concerned.

In the case of the Toarcian in the Paris Basin, the results show close agreement between the values calculated in this manner and the values actually observed.

This also clarifies the problem of the period and the oil formation rate, allowing comparison with the age of the structural movements which determined the formation of the traps. 


\section{FOREWORD}

This study is based on geological, geochemical and digital processing projects completed by Y. Califet-Debyser, G. Deroo, B. Durand, J. Espitalié, M. Louis, J.L. Oudin, R. Pelet and B. Tissot of the Geochemistry Laboratory of the Institut français du pétrole.

\section{INTRODUCTION}

The aim of the geochemical study of a sedimentary basin is to determine the zones in which the oil is formed, and, if possible, for each geological formation, to produce a map of the quantities of oil formed at any point. To do this, it is necessary first to identify the reaction mechanisms of the genesis of the oil and the corresponding kinetics.

The transformations of organic matter in the subsoil depend evidently on its initial composition and, like any chemical reaction, are governed by the temperature, pressure and any catalysts involved. Recent studies, based on observations in sedimentary series and confirmed by laboratory experiments, have demonstrated the important role played by burial related factors, and particularly the temperature. These studies include the work of Louis (1964) and Louis and Tissot (1967) on the Toarcian in the Paris Basin; Philippi (1965) on the Mio-Pliocene in California (Welte, 1966; McIver, 1967 and Vassoevich, 1967).

According to these results, the rise in temperature is the determining factor for the changes in organic matter. It promotes the formation of petroleum compounds, particularly hydrocarbons, from the insoluble organic matter (kerogen) in the sediments (Fig. 1). The hydrocarbon formation rate also varies with burial depth, since it is very low and becomes high below a certain depth, i.e. above a certain temperature threshold.

These observations make it possible to determine directly, for the formation investigated (Toarcian of the Paris Basin, Mio-Pliocene in California, etc.), the zones where organic matter succeeded in producing oil. However, any extension to other formations or other basins raises a difficulty: it becomes immediately clear that the numerical values, for example, the rate of conversion to hydrocarbons, are only valid for the formation where they have been observed. In fact, these values depend on the nature of the organic and inorganic fractions, which varies from one formation to another, and the temperature distribution as a function of time. These are in turn determined by the subsidence and geothermal gradient, i.e. by the geological history, which varies from one basin to another.

In order to generalize the results to other situations, it is therefore necessary to formalize them. This is the aim of the present work, carried out primarily with data of the Toarcian in the Paris Basin, and comprising the following steps:
- review of the data from observations and experiments;

- determination of a synthetic reaction flowsheet, which satisfies the mechanisms observed for the degradation of organic matter in the sediments;

- expression of the kinetics corresponding to this flowsheet;

- computer simulation of the evolution of this flowsheet.

This produces a model which, in certain conditions, serves to simulate the evolution of organic matter in other sedimentary units, or in other basins.

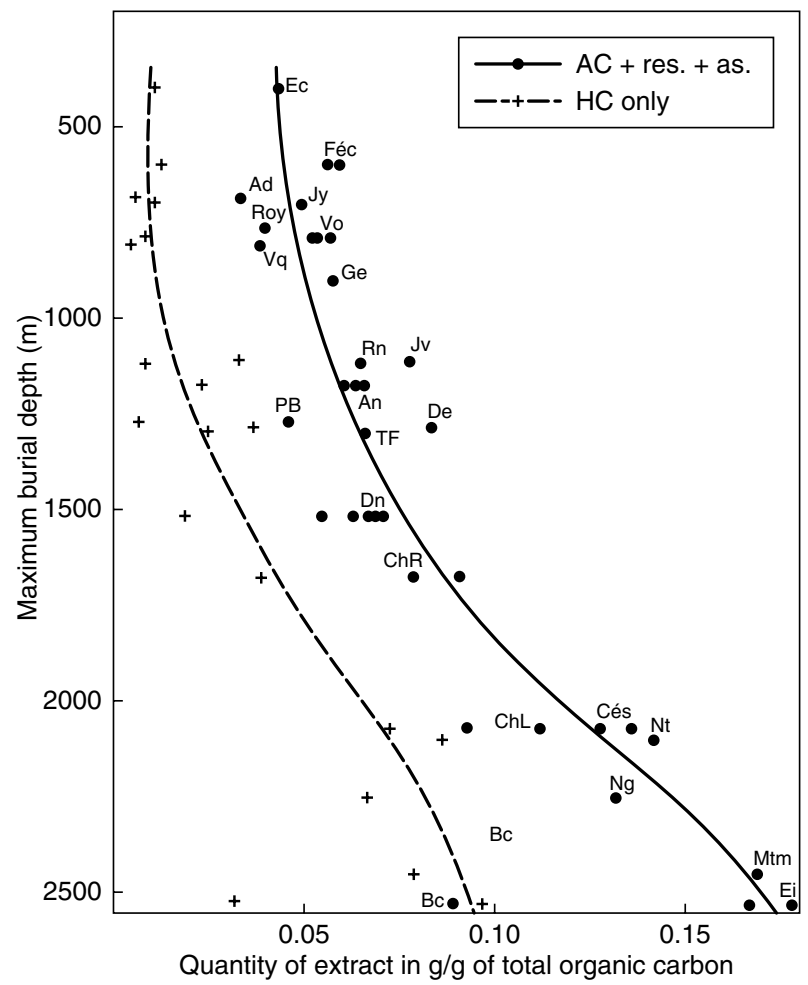

Figure 1

Quantity of hydrocarbons + resins + asphaltenes in the Lower Toarcian clays of the Paris Basin (in grams per gram of total organic carbon), as a function of maximum burial depth.

The study of the kinetics of oil formation brings up another problem, often raised in exploration: that of the "timing" of formation. This is an important point in determining the possibilities of hydrocarbon expulsion and trapping. In fact, we know that a conflict exists between the conditions favorable to the genesis of oil and to its expulsion (Tissot, 1966): oil formation only becomes significant beyond a certain depth threshold; by contrast, the potential for oil expulsion by compaction of the source rock decreases rapidly with increasing burial. The search for an optimum requires the knowledge of the respective rates of oil formation and fluid expulsion. 
It is also important to consider the time when the oil was formed, to compare it with the age of the structural movements conditioning the formation of the traps.

\section{DEFINITION OF COMPONENTS}

The example provided by the Lower Toarcian clays in the Paris Basin is chiefly used for this study. The results of the analyses are given in Louis and Tissot (1967) and in a forthcoming publication that will provide further data. For insoluble organic matter, use is also made of the results on the Devonian and Cretaceous in Canada (McIver, 1967).

It is important to remark how difficult it is to compare the results of analyses conducted in various laboratories, on different bases, which deprives attempts at synthesis of a set of valuable data. It would in particular be necessary to have a protocol of rock extraction and fractionation that has a general value.

In this study, the terms employed to designate the different components of the organic matter are listed in Table 1: the components are separated by their differences of solubility in a scale of solvents. The finely ground rock samples are extracted in the Soxhlet apparatus first by chloroform, then by the triple mixture MAB (methanol 15, acetone 15, benzene 70), until completely depleted. These extracts are respectively called the $\mathrm{CHCl}_{3}$ extract and $M A B$ extract. Insoluble organic carbon is determined on the extracted rock.
The $\mathrm{CHCl}_{3}$ extract is treated with hexane to precipitate a solid component called asphaltene here. Chromatography of the remaining liquid on alumina is used to separate the hydrocarbons and another fraction called resins. A portion of the asphaltenes is insoluble in carbon tetrachloride: thus two fractions are separated called $\mathrm{CCl}_{4}$ soluble asphaltenes and $\mathrm{CCl}_{4}$ insoluble asphaltenes. The term kerogen is applied to the insoluble organic residue after the two extractions. The kerogen is virtually inseparable from the inorganic matter except by destruction of the latter (hydrofluoric acid attack).

The fractionation thus carried out is justified, because it corresponds to a scale of chemical properties (condensation, oxygen content) and physical properties (molecular weights and polarity):

- Table 2 gives the elementary composition of the various heteroatomic compounds.

- Figure 2 shows the relation between condensation (measured by the $\mathrm{C} / \mathrm{H}$ ratio) and the content of oxygen, the most abundant heteroatom; the resins, $\mathrm{CCl}_{4}$ soluble asphaltenes and $\mathrm{CCl}_{4}$ insoluble asphaltenes can be seen to form an orderly succession, in which condensation and oxygen content steadily increase. By contrast, the MAB extract is quite different, being at once richer in heteroatoms and the least condensed.

- The average molecular weights measured increase in the order of hydrocarbons, resins, asphaltenes.

TABLE 1

Separation of organic components of rocks and main analytical methods (The methods of fractionation and detailed analysis of the hydrocarbons are not shown here)

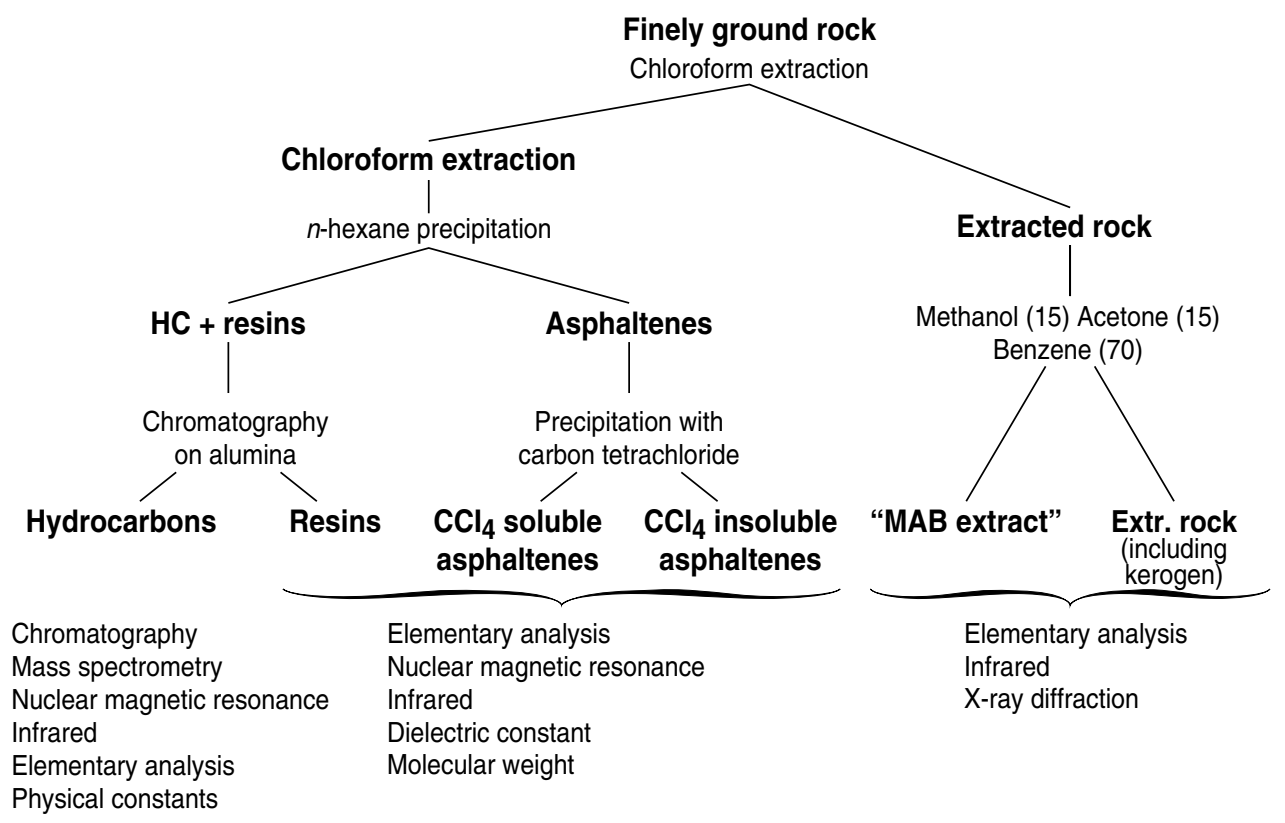


TABLE 2

Elementary composition of MAB extract and resins and asphaltenes extracted from Toarcian clays, compared with that of resins and asphaltenes of crude oils (average values)

\begin{tabular}{l|l|c|c|c|c|c}
\hline Source & \multicolumn{1}{|c|}{ Component } & $\mathrm{C}$ & $\mathrm{H}$ & $\mathrm{C} / \mathrm{H}$ & $\mathrm{O}$ & $\mathrm{O}+\mathrm{N}+\mathrm{S}$ \\
\hline \multirow{2}{*}{ Crude oil } & Resins (average of 14 oils) & 84.0 & 9.2 & 9.17 & & $6.9^{*}$ \\
& Asphaltenes (average of 18 oils) & 85.6 & 8.2 & 10.39 & & $6.2^{*}$ \\
\hline \multirow{3}{*}{ Toarcian } & Resins (average of 27 samples from 16 boreholes) & 76.9 & 9.2 & 8.37 & 6.8 & 10.1 \\
extracts & $\mathrm{CCl}_{4}$ soluble asphaltenes (average of 24 samples from 16 boreholes) & 72.1 & 7.5 & 9.67 & 9.2 & 13.3 \\
& $\mathrm{CCl}_{4}$ insoluble asphaltenes (average of 22 samples from 16 boreholes) & 69.8 & 6.8 & 10.37 & 13.9 & 17.5 \\
& $\mathrm{MAB}$ extract (average of 28 samples from 20 boreholes) & 70.1 & 8.4 & 8.40 & 16.0 & 20.3 \\
\hline
\end{tabular}

$* 100-(\mathrm{C}+\mathrm{H})$

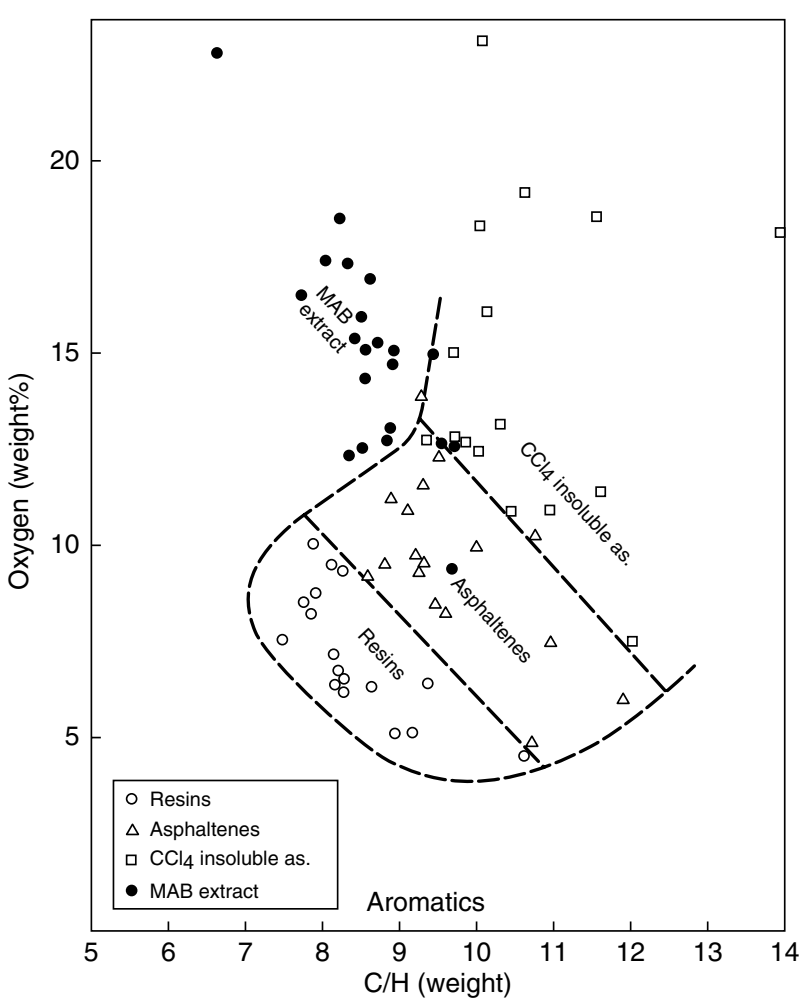

Figure 2

Carbon/hydrogen ratio and oxygen content of various components extracted from Toarcian clays from the Paris Basin.

- Table 3 shows the behavior of the dielectric constants for solutions in chloroform; they increase in the order of resins and $\mathrm{CCl}_{4}$ soluble asphaltenes, $\mathrm{CCl}_{4}$ insoluble asphaltenes. The MAB extracts are even more polar, cannot be extracted by chloroform, and demand highly polar solvents for extraction.

The various extractable components shown in Table 1 hence display clearly circumscribed ranges of physical and chemical properties. The same does not apply to kerogen, whose properties vary with the original organic matter, time and depth: elementary composition (Table 4), and structure (see infrared diagrams, Fig. 10). This is not surprising because kerogen is defined as a residue in the above extraction protocol. To a lesser extent, the remark can be applied to MAB extract whose elementary composition can also vary (Fig. 2).

\section{TABLE 3}

Dielectric constant of resins and asphaltenes

The dielectric constant $\varepsilon$ was measured with a frequency of $1 \mathrm{MHz}$ and at $10^{\circ} \mathrm{C}$, for heavy products in solution in chloroform in a concentration of $20 \mathrm{~g} / \mathrm{l}$

\begin{tabular}{l|c|c|c}
\hline \multicolumn{1}{c|}{ Component } & $\begin{array}{c}\text { Number } \\
\text { of samples }\end{array}$ & Mean $\varepsilon$ & $\begin{array}{c}\text { Standard } \\
\text { deviation }\end{array}$ \\
\hline Pure chloroform & & 5.2 & \\
\hline Resins & 10 & 5.32 & 0.02 \\
\hline $\mathrm{CCl}_{4}$ soluble asphaltenes & 11 & 6.30 & 0.55 \\
& 10 & 6.15 & 0.18 \\
\hline $\mathrm{CCl}_{4}$ insoluble asphaltenes & 6 & 6.82 & 0.20 \\
\hline
\end{tabular}

After J.L. Oudin

TABLE 4

Elementary composition of insoluble organic matter (kerogen) of the Devonian and Cretaceous in Canada (mean values)

\begin{tabular}{l|c|r|r}
\hline Depth $(\mathrm{m})$ & Number of samples & $\mathrm{C} / \mathrm{H}$ & $\mathrm{O}$ \\
\hline$<1500$ & 20 & 13.0 & 15.9 \\
$>1500$ & 7 & 18.6 & 6.3 \\
\hline
\end{tabular}

Elementary composition of insoluble organic matter (kerogen) lower Toarcian in the Paris Basin (mean values)

\begin{tabular}{l|c|c|c}
\hline Depth $(\mathrm{m})$ & Number of samples & $\mathrm{C} / \mathrm{H}$ & $\mathrm{O}$ \\
\hline 700 to 2500 & 10 & 11.8 & 12.7 \\
\hline
\end{tabular}

After McIver, 1967 


\section{REVIEW OF DATA FROM OBSERVATIONS AND EXPERIMENTS ON THE GENERAL MECHANISM OF THE EVOLUTION OF ORGANIC MATTER}

\subsection{General: Method of Representation}

The system consisting of the mass of rock containing $1 \mathrm{~g}$ of organic carbon (quantity easily accessible to measurement) is considered, in any form whatsoever; this quantity corresponds to about $1.3 \mathrm{~g}$ of soluble and insoluble total organic compounds. This definition assumes that the migration effect is ignored (which appears plausible in the case of the Toarcian in the Paris Basin) as well as the loss of light compounds $\left(\mathrm{CO}_{2}, \mathrm{H}_{2} \mathrm{O}\right.$ and light hydrocarbons) which are entrained by the waters or lost in the laboratory during the extractions.

The two studies mentioned (Toarcian in the Paris Basin, Devonian and Cretaceous in Canada) revealed that the temperature rise is the determining factor for the evolution of organic matter. This temperature rise promotes the appearance of petroleum compounds (Fig. 1), and hydrocarbons in particular, at the expense of kerogen, according to a flowsheet shown in Figure 3 (Louis and Tissot, 1967).

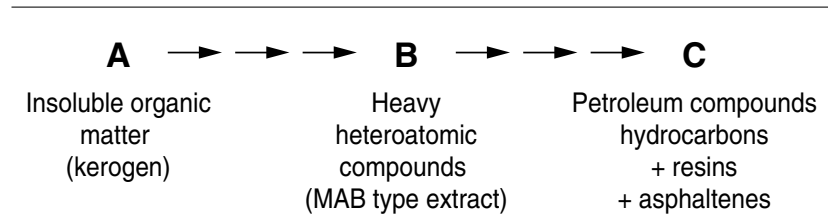

Figure 3

Synthetic reaction flowsheet inferred from observations and experiments on the Toarcian in the Paris Basin.

Each of the terms A and B actually represents a large number of individual compounds which are formed simultaneously or in succession.

The mutual relations of the different components in the example of the Paris Basin are clarified by Figures 4 and 5 . These figures show, as a function of the maximum depth (i.e. the maximum temperatures) reached by the sample, the advancement of the transformation $\mathrm{A} \rightarrow \mathrm{B} \rightarrow \mathrm{C}$ (Fig. 4), and the transformation $\mathrm{B} \rightarrow \mathrm{C}$ alone. These graphs resemble those normally employed to monitor the kinetics of a reaction, but are different in two aspects:

- on the $x$-axis, time is not plotted, but the maximum burial depth, which integrates the time and the subsidence rate;

- the $y$-axis does not show the concentrations, but the fraction of total carbon present in each component A, B, $\mathrm{C}$, the latter being separated into hydrocarbons (AC), and resins and asphaltenes (RA).

For example, the fraction of total carbon present in hydrocarbons is defined as follows:

$\left[\mathrm{C}_{\mathrm{HC}}\right]=$ quantity of hydrocarbons $\times \mathrm{HC}$ carbon content (related to $1 \mathrm{~g}$ of $\mathrm{C}_{\text {total organic }}$ ) (elementary analysis)

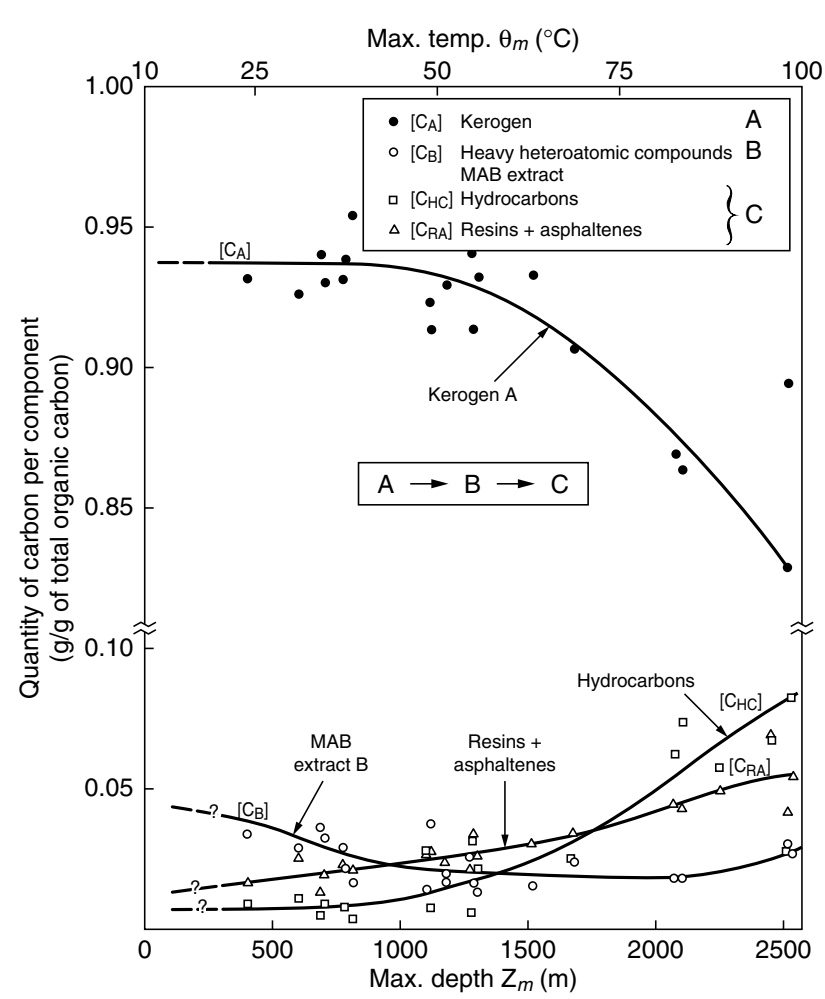

Figure 4

Evolution of the transformation $\mathrm{A} \rightarrow \mathrm{B} \rightarrow \mathrm{C}$ as a function of depth and maximum temperature reached (Lower Toarcian in the Paris Basin)

The advancement of the reaction is measured by the quantity of carbon present in the different components, the total being related to $1 \mathrm{~g}$ of total organic carbon. The quantities $\left[\mathrm{C}_{\mathrm{A}}\right]$, $\left[\mathrm{C}_{\mathrm{B}}\right],\left[\mathrm{C}_{\mathrm{HC}}\right],\left[\mathrm{C}_{\mathrm{RA}}\right]$ are defined as follows:

$$
\begin{aligned}
& {\left[\mathrm{C}_{\mathrm{HC}}\right]=\begin{array}{c}
\text { quantity of } \\
\text { hydrocarbons }
\end{array} \times \begin{array}{c}
\text { carbon content } \\
\text { of hydrocarbons }
\end{array}} \\
& \text { (related to } 1 \mathrm{~g} \text { of total (elementary } \\
& \text { organic carbon) analysis) } \\
& {\left[\mathrm{C}_{\mathrm{A}}\right]+\left[\mathrm{C}_{\mathrm{B}}\right]+\left[\mathrm{C}_{\mathrm{HC}}\right]+\left[\mathrm{C}_{\mathrm{RA}}\right]+\left[\mathrm{C}_{\text {losses }}\right]=1}
\end{aligned}
$$

and similarly $\left[\mathrm{C}_{\mathrm{A}}\right],\left[\mathrm{C}_{\mathrm{B}}\right],\left[\mathrm{C}_{\mathrm{RA}}\right]$. We therefore have the equations:

- in Figure 4: $\left[\mathrm{C}_{\mathrm{A}}\right]+\left[\mathrm{C}_{\mathrm{B}}\right]+\left[\mathrm{C}_{\mathrm{HC}}\right]+\left[\mathrm{C}_{\mathrm{RA}}\right]+\left[\mathrm{C}_{\text {losses }}\right]=1$

- in Figure 5: $\left[\mathrm{C}_{\mathrm{B}}\right]+\left[\mathrm{C}_{\mathrm{HC}}\right]+\left[\mathrm{C}_{\mathrm{RA}}\right]+\left[\mathrm{C}_{\text {losses }}\right]=1$.

The value of using this parameter is that the quantity $\left[\mathrm{C}_{\mathrm{A}}\right]$ is the only one that is easy to measure in the kerogen; besides, it offers a better picture of the advancement of the reactions, in view of the remark on the variations composition of the kerogen and of the MAB extract made in Section 1: hence it is the only method that allows for a single parameter to represent the different contents.

Figures 4 and 5 explain why, in the flowsheet of Figure 3, the heavy heteroatomic compounds (MAB extract) are made to play the role of a necessary intermediate between 


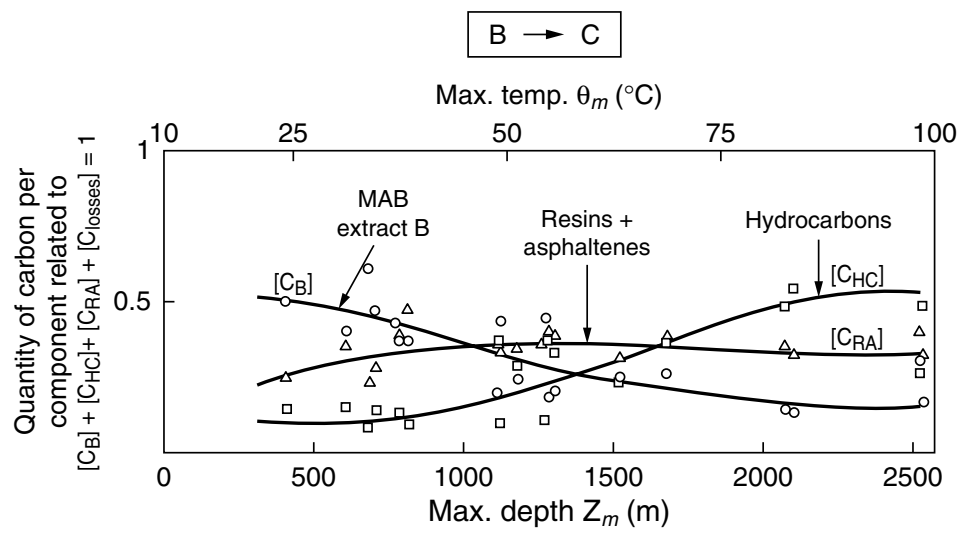

Figure 5

Evolution of the transformation $\mathrm{B} \rightarrow \mathrm{C}$ as a function of depth and maximum temperature reached (Lower Toarcian in the Paris Basin).

The advancement of the reactions measured by the quantity of carbon present in the different components. The quantities $\left[\mathrm{C}_{\mathrm{B}}\right],\left[\mathrm{C}_{\mathrm{HC}}\right],\left[\mathrm{C}_{\mathrm{RA}}\right]$ are defined as in Figure 4. We obtain the equation:

For the meaning of the symbols, refer to Figure 4.

$$
\left[\mathrm{C}_{\mathrm{B}}\right]+\left[\mathrm{C}_{\mathrm{HC}}\right]+\left[\mathrm{C}_{\mathrm{RA}}\right]+\left[\mathrm{C}_{\text {losses }}\right]=1
$$

kerogen $\mathrm{A}$ and the compounds of oil $\mathrm{C}$. This assumption is based on the rapid decrease of this extract (Figs. 4 and 5) in the domain where large quantities of hydrocarbons are formed. To confirm this, Louis and Tissot (1967) conducted an experiment with the same samples of the Toarcian from Paris Basin. The hydrocarbons, resins and asphaltenes were removed by solvent extraction. Only the kerogen and heavy heteroatomic compounds (MAB extract) remained in the rock. The samples were then raised in the laboratory to pressures and temperatures corresponding to those of a deep basin $\left(180^{\circ} \mathrm{C}\right)$. The formation of new hydrocarbons, resins and asphaltenes was observed, but this formation was preceded by the formation of a new quantity of MAB extract.

Let us first examine the relations between the temperature and the contents observed on the natural examples, and then consider the problem of transformation rates.

\subsection{Content-Temperature Relations}

The observation made on the Toarcian of the Paris Basin revealed a very strong link between the quantity of compounds of oil $\mathrm{C}$ formed and the maximum depth, i.e. the maximum temperature $\theta_{m}$ to which the samples were raised (Fig. 1). The graphs show that the same applies to each of the groups of reactions $\mathrm{A} \rightarrow \mathrm{B}$ and $\mathrm{B} \rightarrow \mathrm{C}$, and, in the latter case, for various groups of products formed.

Figure 4 shows the quantity of A transformed, i.e. the advancement of the first group of reactions as a function of depth. The temperature rise strongly favors reactions of the type $\mathrm{A} \rightarrow \mathrm{B}$, but this influence is only significant above 60 $65^{\circ} \mathrm{C}$. Below this temperature, the temperature dependence is slight and the quantities of $\mathrm{B}$ and $\mathrm{C}$ observed largely originate from the hydrocarbons and other compounds preexisting in the recent sediments.

A parallel can be drawn between this fact and the observations of McIver (Fig. 6): in kerogen A, the degree of condensation marked by the $\mathrm{C} / \mathrm{H}$ ratio varies first slightly with depth, and then increases sharply in a depth range comparable to the previous one.

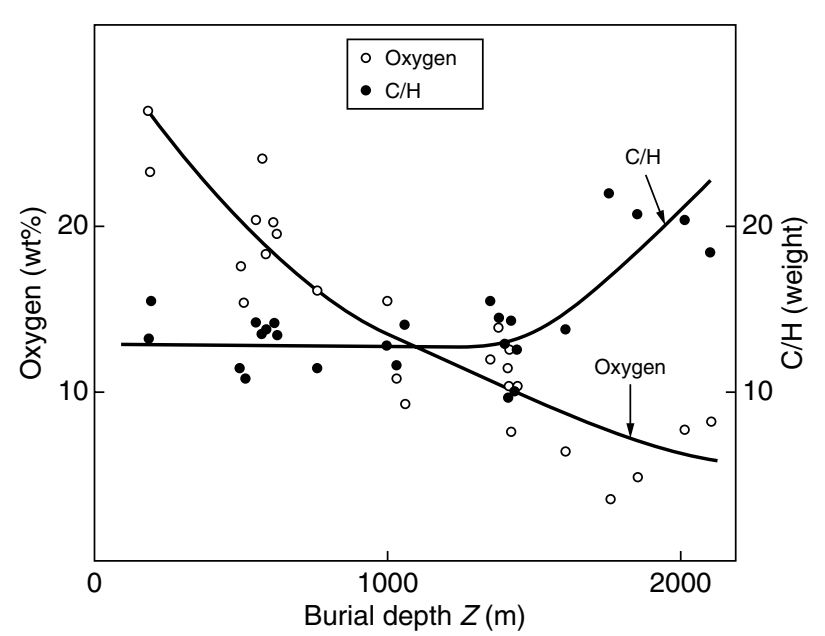

Figure 6

Variation in the elementary composition of kerogen of the Devonian and Cretaceous in Canada, as a function of burial depth (after the data of McIver, 1967).

In natural conditions, transformation $\mathrm{A} \rightarrow \mathrm{B}$ is far from complete. The fraction of total carbon remaining in the raw material A varies from 0.95 for shallow samples to 0.85 for samples raised to the highest temperatures $\left(100^{\circ} \mathrm{C}\right)$ in the 
TABLE 5

List of notations

1. Time, depth and temperature

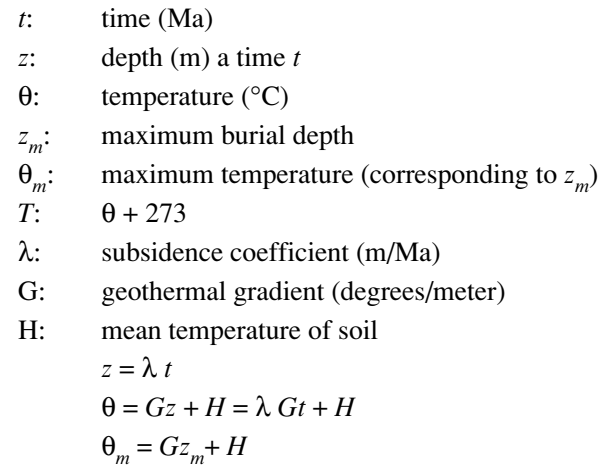

\section{Subsidence law}

In the following simple cases considered, it suffices to represent the example of the Toarcian: burial up to $t_{1}$, followed by erosion. For $t \leq t_{1} \quad \lambda_{1}>0 \quad Z=\lambda_{1} t$

For $t>t_{1} \quad \lambda_{2}<0 \quad Z=\lambda_{1} t_{1}+\lambda_{2}\left(t-t_{1}\right)=Z_{m}+\lambda_{2}\left(t-t_{1}\right)$

\section{Extractable compounds}

\begin{tabular}{|c|c|c|c|}
\hline \multirow{2}{*}{ Type } & \multirow{2}{*}{ Designation } & \multicolumn{2}{|c|}{$\begin{array}{c}\text { Quantify for a system } \\
\text { defined by } 1 \mathrm{~g} \text { of total organic carbon }\end{array}$} \\
\hline & & $\begin{array}{c}\text { At origin } \\
t=0\end{array}$ & $\begin{array}{c}\text { At time } \\
t\end{array}$ \\
\hline Insoluble organic matter (kerogen) & A & $x_{0}$ & $x$ \\
\hline Heavy heteroatomic compounds extracted with mixture MAB & B & $y_{0}$ & $y$ \\
\hline Hydrocarbons + resins + asphaltenes & $\mathrm{C}$ & $u_{0}$ & $u$ \\
\hline Hydrocarbons only & $\mathrm{HC}$ & $v_{0}$ & $v$ \\
\hline Resins and asphaltenes & RA & $w_{0}$ & $w$ \\
\hline
\end{tabular}

4. Rate of formation of $\mathrm{C}$

$$
\begin{array}{ll}
\text { At constant temperature } & V_{\theta}=\left(\frac{\mathrm{d} u}{\mathrm{~d} t}\right)_{\theta} . \\
\text { At constant subsidence } & V_{\lambda}=\left(\frac{\mathrm{d} u}{\mathrm{~d} t}\right)_{\lambda}
\end{array}
$$

case of the Toarcian of the Paris Basin. This part of organic matter can moreover be artificially decomposed: in the oil shale industry, at around $500^{\circ} \mathrm{C}$, it can be converted to "shale oil" and gas, except for a cokefied fraction which represents about $20 \%$ of the total organic carbon.

Figure 5 shows that transformation $\mathrm{B} \rightarrow \mathrm{C}$ depends considerably on the temperature: this promotes the formation of the compounds of oil $\mathrm{C}$, from the heavy heteroatomic compounds $\mathrm{B}$. The total quantity of $\mathrm{C}$ (hydrocarbons + resins + asphaltenes) is observed to vary approximately exponentially with $1 / T$ (Fig. 7). T represents the absolute temperature $\left(\theta_{m}+273\right)$ to which each sample was raised in the basin.
Within this group of reactions $\mathrm{B} \rightarrow \mathrm{C}$, the temperature rise favors certain products at the expense of others. Thus the ratio of hydrocarbons/resins + asphaltenes increases with temperature and also displays an exponential variation with $1 / T$ (Fig. 8). Among the saturated hydrocarbons, the formation of alkanes and cyclanes with a single ring is favored by the increase in temperature, while the polycyclic saturated hydrocarbons (cyclanes with 3, 4, 5 and 6 rings), and the optical activity associated with them decrease sharply (Louis and Tissot, 1967).

These remarks also confirmed a statistical observation, valid at world scale: the density of the crude oils, and their 


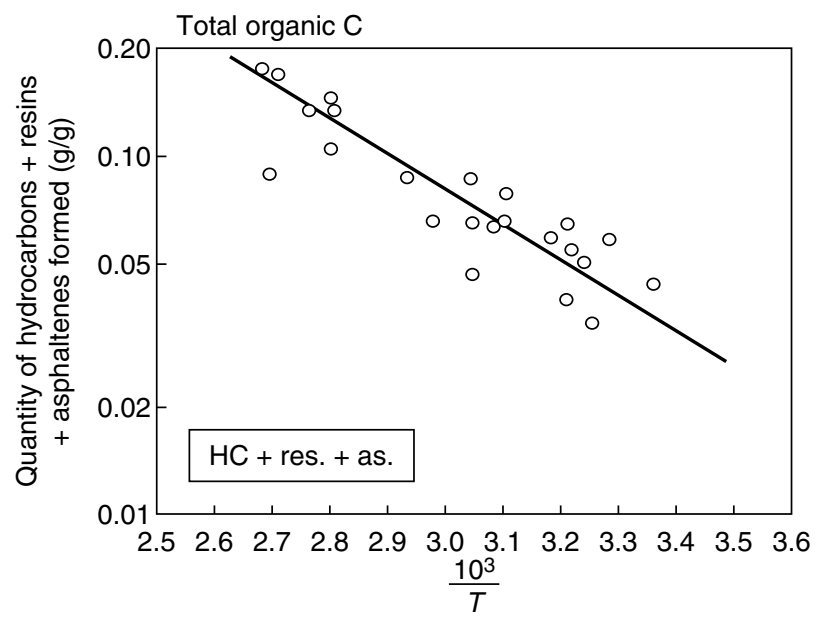

Figure 7

Variation in the quantity of hydrocarbons + resins + asphaltenes formed as a function of maximum temperature reached $T$ in kelvin (Lower Toarcian in the Paris Basin).

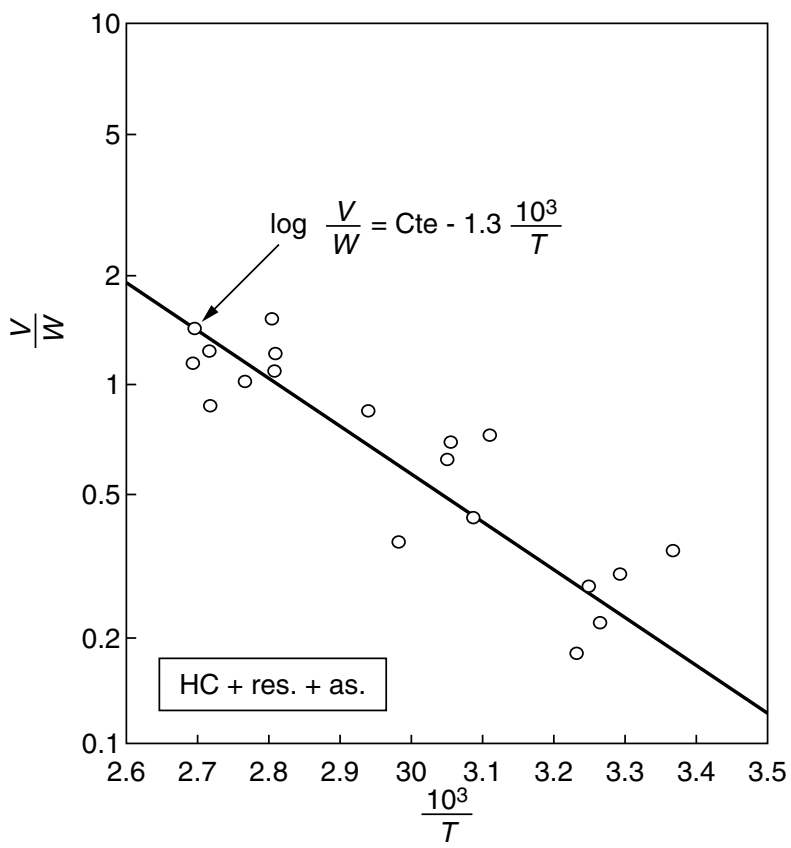

Figure 8

Variation in ratio $\frac{v}{w}=\frac{\text { hydrocarbons }}{\text { resins }+ \text { asphaltenes }}$ as a function of maximum temperature $T$ in kelvin (Lower Toarcian of the eastern half of the Paris Basin).

total cyclane content decreases with the depth of the reservoir, and hence with rising temperature.

It may be observed that Figures 7 and 8 imply a kinetics wherein the degree of advancement of the reactions varies with temperature according to an Arrhenius' type law.

\subsection{Content-Time Relations}

The depth and temperature of a sediment are both related to time by the subsidence $\lambda$, i.e. the burial rate measured in meters per million years. In each time interval where subsidence is constant, the depth and temperature are a linear function of time (see Table 5 for notations meaning).

All the Toarcian samples analyzed were first buried (subsidence $\lambda_{1}>0$ ) up to time $t=t_{1}$, which reached 25 to $150 \cdot 10^{6}$ years depending on each case, followed by a rise to the surface $\left(\lambda_{2}<0\right)$ up to the Present $t_{2}=180 \cdot 10^{6}$ years. For many of them, the mean value of $\lambda_{1}$ is close to $15 \mathrm{~m} / \mathrm{Ma}$ (between 13 and 17).

If a sample raised to temperature $\theta_{m}$ is brought to the surface and cools, it can be assumed that the reaction is "frozen", especially if cooling is rapid (highly negative $\lambda_{2}$ ). Theoretical calculations from the equations given in Chapter 4 show that as a first approximation, this assumption is acceptable. In these conditions, to have an approximate value of the quantities of hydrocarbons, resins and asphaltenes formed at time $t_{1}$ for a subsidence $15 \mathrm{~m} / 10^{6}$ years, use is made of the values currently measured on the samples subjected to this subsidence up to $t_{1}$.

We finally obtain Figure 9, determined from Figure 1, by eliminating the samples whose subsidence is less than 13 or

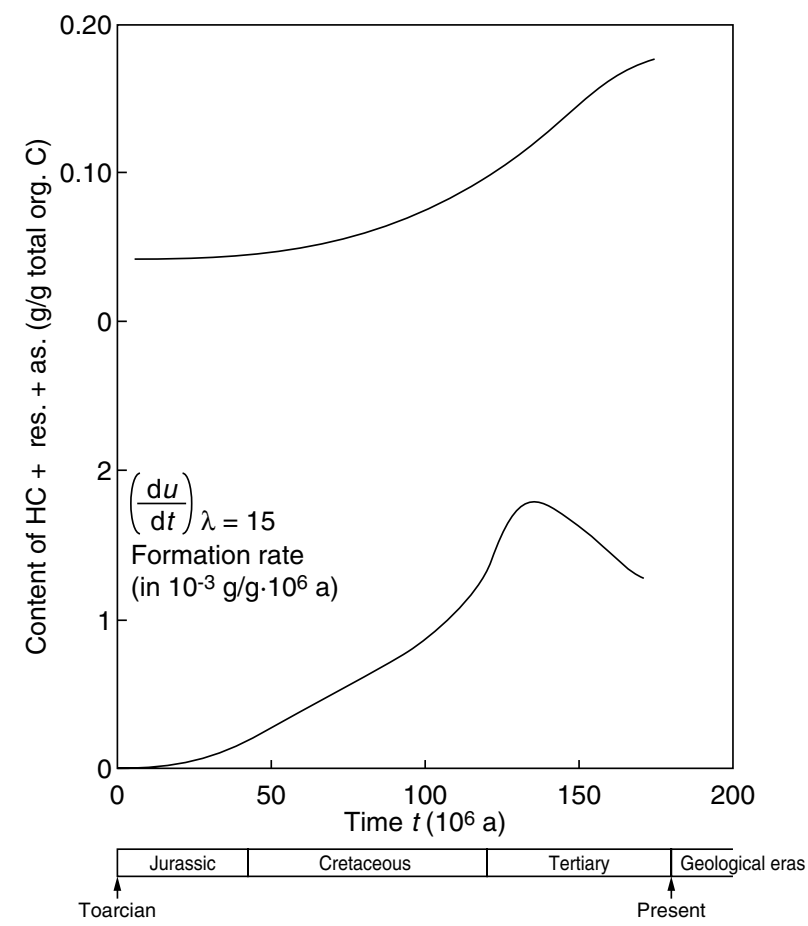

Figure 9

Reconstruction of the content of hydrocarbons + resins + asphaltenes and their rate of formation, as a function of time, for $1 \mathrm{~g}$ of total organic carbon and for a subsidence $\lambda=15 \mathrm{~m} / 10^{6}$ years (Lower Toarcian in the Paris Basin). 
greater than $17 \mathrm{~m} / 10^{6}$ years, and by converting the maximum depths $Z_{m}$ into subsidence time $t_{1}$ by the equation $Z_{m}=\lambda_{1} t_{1}$.

It is easy to see that in Figure 9, the formation of hydrocarbons only becomes effective after a long induction period, since this is the time necessary for burial of the formation to a depth equal to that of the threshold already identified.

\subsection{Rate-Time Relations}

An attempt can also be made to evaluate the formation rates of the compounds of oil $\mathrm{C}$ and hydrocarbons at constant subsidence. Let $u$ denote the quantity of $\mathrm{C}$ (hydrocarbons + resins + asphaltenes) at time $t$ and per gram of total organic carbon; $v$ is a quantity of hydrocarbons per gram of total organic carbon. The rates are:

$$
\left(\frac{\mathrm{d} u}{\mathrm{~d} t}\right)_{\lambda=\mathrm{Cte}}\left(\frac{\mathrm{d} v}{\mathrm{~d} t}\right)_{\lambda=\mathrm{Cte}}
$$

Using the same assumptions as above, we can start with Figure 1 which gives $n$ and $u$ as a function of $z$ and constitutes the base document.

We have the general equation:

$$
\mathrm{d} u=\left(\frac{\partial u}{\partial t}\right)_{\theta} \mathrm{d} t+\left(\frac{\partial u}{\partial \theta}\right)_{t} \mathrm{~d} \theta
$$

In a transformation at constant $\lambda$, we obtain:

$$
\left(\frac{\mathrm{d} u}{\mathrm{~d} t}\right)_{\lambda}=\left(\frac{\partial u}{\partial t}\right)_{\theta}+\left(\frac{\partial u}{\partial \theta}\right)_{t} \cdot\left(\frac{\mathrm{d} \theta}{\mathrm{d} t}\right)_{\lambda}=\left(\frac{\partial u}{\partial t}\right)_{\theta}+\lambda G\left(\frac{\partial u}{\partial \theta}\right)_{t}
$$

and furthermore:

$$
\begin{aligned}
\left(\frac{\mathrm{d} u}{\mathrm{~d} z}\right)_{\lambda}=\left(\frac{\partial u}{\partial t}\right)_{\theta} \cdot\left(\frac{\mathrm{d} t}{\mathrm{~d} z}\right)_{\lambda} & +\left(\frac{\partial u}{\partial \theta}\right)_{t} \cdot\left(\frac{\mathrm{d} \theta}{\mathrm{d} z}\right)_{\lambda} \\
& =\frac{1}{\lambda}\left(\frac{\partial u}{\partial t}\right)_{\theta}+G\left(\frac{\partial u}{\partial \theta}\right)_{t}
\end{aligned}
$$

hence:

$$
\left(\frac{\mathrm{d} u}{\mathrm{~d} t}\right)_{\lambda}=\lambda\left(\frac{\mathrm{d} u}{\mathrm{~d} z}\right)_{\lambda}
$$

Hence only the points corresponding to $\lambda$ close to fifteen are selected from Figure $1,\left(\frac{\mathrm{d} u}{\mathrm{~d} t}\right)_{\lambda}$ and $\left(\frac{\mathrm{d} v}{\mathrm{~d} t}\right)_{\lambda}$ are calculated from $\frac{\mathrm{d} u}{\mathrm{~d} z}$ and $\frac{\mathrm{d} v}{\mathrm{~d} z}$. The results are shown in Figure 9 for the formation rate of all the oil compounds $\left(\frac{\mathrm{d} u}{\mathrm{~d} t}\right)_{\lambda}$ and for a subsidence of $15 \mathrm{~m} / 10^{6}$ years.
This confirms that the formation rates are far from constant. In the case of the Toarcian in the Paris Basin, they only have a significant value from the Middle Cretaceous to the Present (between 75 and $180 \cdot 10^{6}$ years) peaking in the Early Tertiary.

\section{ESTABLISHMENT OF A REACTION FLOWSHEET}

\subsection{The Original Organic Matter}

We now leave behind the region of facts established from analytical data to enter the region of interpretation. This will rely on a number of simplifying assumptions, which can be justified if they culminate in relations between the parameters that are confirmed by actual data. In particular, given the large number of individual components, most of them are unknown, we shall have to treat as an overall transformation what is in fact a series of successive or parallel reactions. We obviously run the danger of advancing too far along this route.

Living organic matter is the original material from which all organic products found in the sediments are developed. In the free state, it can be fractionated and its analysis shows that it is nearly entirely composed of proteins, carbohydrates, lipids and lignin.

On the floor of the seas and lakes, the freshly deposited sediments are the seat of considerable microorganism activity (particularly bacteria). In aerobic medium, the organic matter is rapidly destroyed; by contrast, in impermeable rocks (clay, fine limestone mud), the medium rapidly becomes closed, the oxygen present is consumed, and an anaerobic regime is installed, so that part of the organic material is not destroyed.

The activity of the microorganisms decreases very rapidly: it is divided by 20 around $70 \mathrm{~cm}$ depth, and there is practically no active life beyond 10 to $15 \mathrm{~m}$. At the same time, a very sharp decrease is observed in the simple organic compounds that can be separated and determined (sugars, amino acids, even fatty acids). Nearly all the remaining organic matter (more than $80 \%$ ) consists of kerogen, a poorly defined compound, in commonly used solvents, and whose structure is poorly known.

It can be assumed that kerogen represents the residue inassimilable by the microorganisms. The disappearance of the microorganisms can be simply explained by the disappearance of the compounds necessary for their nourishment, as in case of a closed culture medium which peaks and declines over time. The action of the microorganisms, and perhaps of certain inorganic species, could explain the appearance of a macromolecular structure in very moderate temperature conditions.

In the rest of this discussion, we shall focus on the kerogen degradation reactions, leading to the formation of most of the oil; we shall no longer discuss hydrocarbons, 
Figure 10

Infrared spectra of kerogen samples of the Toarcian in the Paris Basin, showing the evolution of the structure according to the burial depth (M. Pennequin).

Attribution of absorption bands:

1) $2.82 \mu\left(3450 \mathrm{~cm}^{-1}\right)$ :

$\mathrm{OH}$ stretching

2) $3.25-3.50 \mu\left(3080-2860 \mathrm{~cm}^{-1}\right)$ : $\mathrm{CH}_{2}$ and $\mathrm{CH}_{3}$ stretching

3) $5.80 \mu\left(1725 \mathrm{~cm}^{-1}\right)$ : $\mathrm{C}=\mathrm{O}$

4) $6.05-6.25 \mu\left(1650-1600 \mathrm{~cm}^{-1}\right)$ : $\mathrm{H}_{2} \mathrm{O}$ deformation and $\mathrm{C}=\mathrm{C}$ aromatic

5) $6.82 \mu\left(1466 \mathrm{~cm}^{-1}\right)$ : asymmetric $\mathrm{CH}_{3}$ bending

6) $7.20-7.30 \mu\left(1389-1370 \mathrm{~cm}^{-1}\right)$ : $\mathrm{CH}_{2}$ bending and $\mathrm{CH}_{3}$ asymmetric bending

7) $9.85 \mu\left(1015 \mathrm{~cm}^{-1}\right)$ : $\mathrm{C}-\mathrm{O}-\mathrm{C}$ aromatic?

8) $9,10,11.10$ to $13.33 \mu\left(900-750 \mathrm{~cm}^{-1}\right)$ : protons adjacent to aromatic rings

11) $13.80\left(725 \mathrm{~cm}^{-1}\right)$ : $\left(\mathrm{CH}_{2}\right)_{n}, n \geq 3$ ?

It may be observed that:

1) The $\mathrm{C}=\mathrm{O}$ band at $1725 \mathrm{~cm}^{-1}$ decreases with increasing depth (see also Fig. 11).

2) Bands 8, 9, 10 grow with depth. The attributions made after Erdman (1965).

The aromatic $\mathrm{C}=\mathrm{C}$ band 4 also increases.
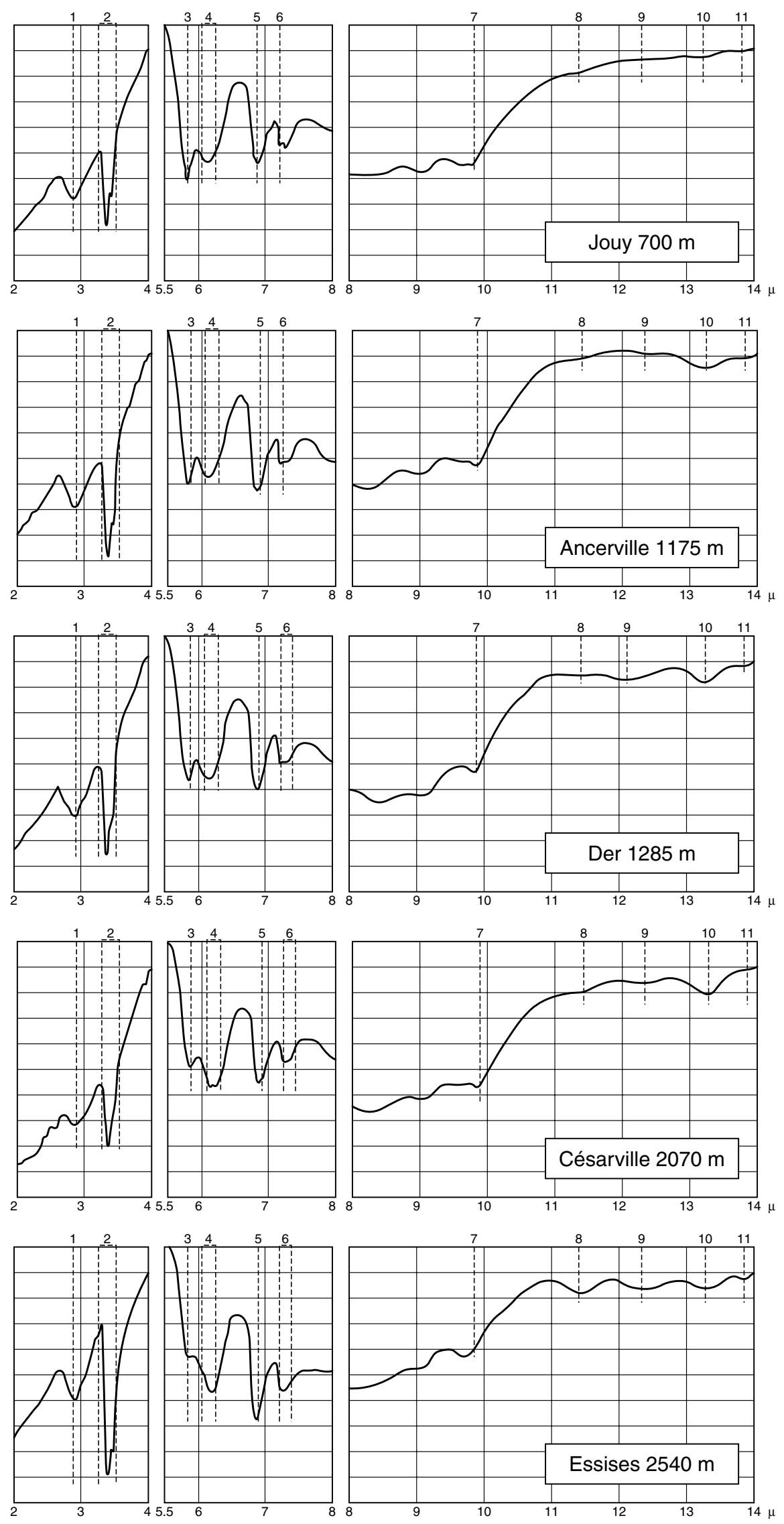
lipids, amino-acids and other compounds which exist in the recent sediment alongside the kerogen. However, they cannot be ignored: they could be the source of the compounds found at rather shallow depths (less than $1000 \mathrm{~m}$ ) in the Toarcian in the Paris Basin, and in particular:

- polycyclic cyclanes possessing optical activity (Louis and Tissot, 1967), from steroids, triterpenoids, etc.;

- porphyrines, from chlorophyls; pristine, phytane etc., from phytyl chains;

- predominantly odd numbered $n$-alkanes, from fatty acids.

Although these compounds subsequently account for a minor part of the oil, because diluted among the more abundant compounds formed at the higher temperature, they remain an invaluable indication of the original organic matter.

\subsection{Structure and Transformation of Kerogen}

In the absence of a satisfactory definition and effective analytical method, the structure of kerogen is poorly known. We can nonetheless try to represent it with a few data obtained by thermal degradation, X-ray diffraction and infrared, and by analogy with the structures proposed for coals. It is a macromolecule, a sort of giant polymer, probably three-dimensional. The more condensed nuclei consist of naphtheno-aromatic structures; the bonds between these nuclei, or with other less condensed structures are mainly of the heteroatomic type.

Insofar as burial and temperature increase, these bonds (such as $\mathrm{C}-\mathrm{S}, \mathrm{C}-\mathrm{O}$, sometimes $\mathrm{C}-\mathrm{C}$ ) break in succession and the polycondensation intensifies (visible in infrared). The splitting of these bonds expels a part of the oxygen and the other heteroatoms in the form of light products $\left(\mathrm{H}_{2} \mathrm{O}, \mathrm{CO}_{2}\right.$ etc.), and liberate structures smaller than kerogen (extractable by solvents) such as the MAB extracts. These structures are still heteroatomic and probably have a high molecular weight, but they represent an important step between the kerogen and the petroleum compounds. However, the residual kerogen becomes more condensed: the carbonhydrogen ratio increases, while oxygen and nitrogen decrease (Fig. 6); in infrared spectrometry (Pennequin, Fig. 10), the carbonyl band decreases with the production of the petroleum compounds (Fig. 11) and the band corresponding to the aromatic group increases; at the same time, the patterned organic matter, visible under the microscope (spores, pollens, etc.), displays increasing carbonization, going from light yellow to brown and then to black (Correia, 1967 and Fig. 12). At extreme depths, the kerogen evolves towards the structure of graphite (appearance of graphite 0002 peak under X-ray diffraction) perhaps by development of graphitic islands within the kerogen (Long et al., 1968).

Similarly, the heavy heteroatomic compounds (MAB extract type) undergo a progressive rearrangement, with a loss of bonding heteroatoms and disproportionation to form a range of products extending from hydrocarbons to the heavy and highly condensed structures. At extreme depth (very high

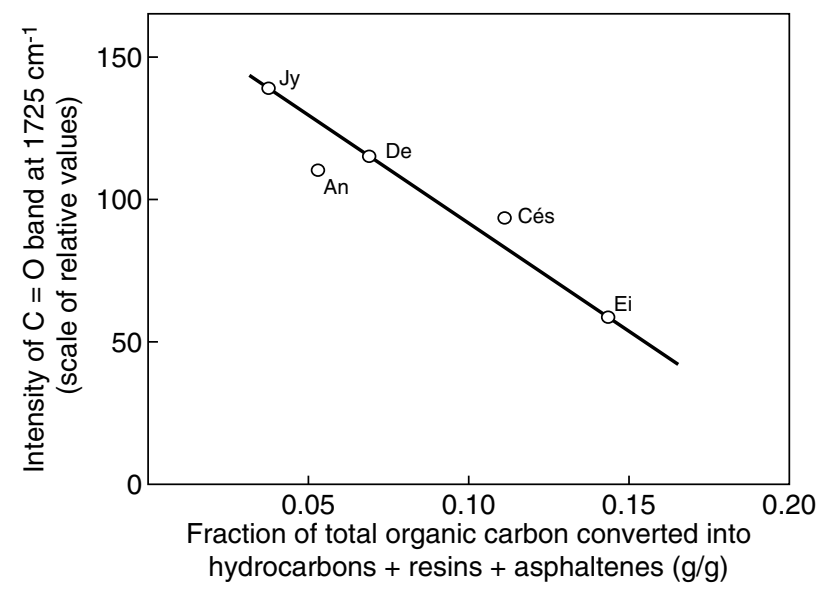

Figure 11

Relation between the formation of petroleum compounds and the decrease of the carbonyl function on kerogen (after the infrared spectra of M. Pennequin).

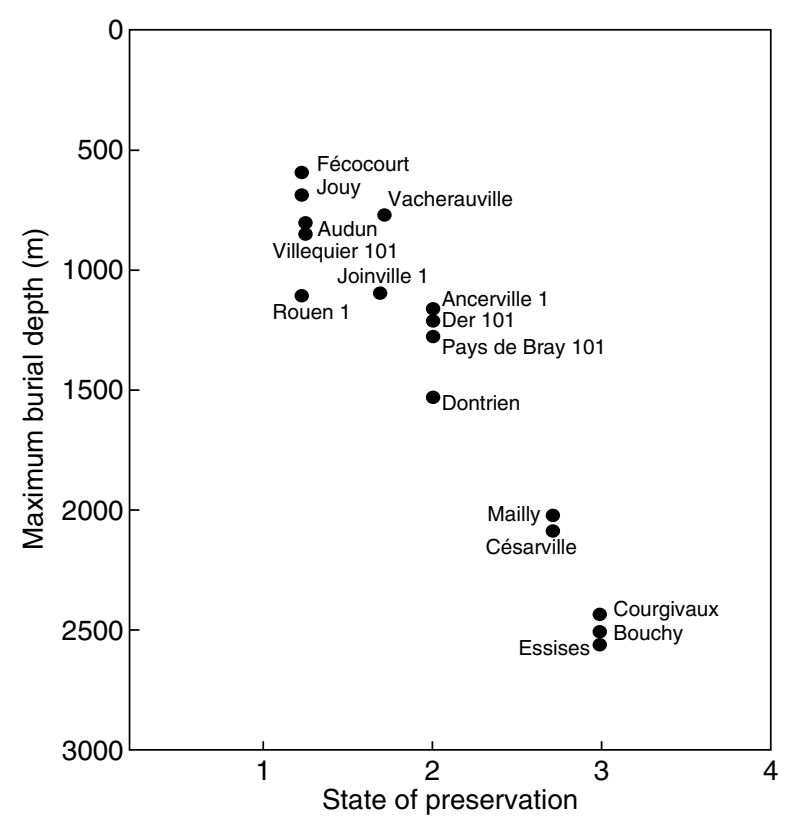

Figure 12

Variation in state of preservation of patterned elements of organic matter as a function of maximum burial depth. (Lower Toarcian in the Paris Basin) (M. Correia).

The spores, pollen grains and other fragments making up the patterned elements of the organic matter visible under the microscope, depending on their variable coloration from yellow to black, help to identify different states of preservation. 
temperatures), this evolution continues towards methane and towards graphite.

All of these transformations can be summarized by the reaction flowsheet in Figure 13a. The elementary composition $(\mathrm{C}, \mathrm{H}, \mathrm{O})$ of the kerogen and extractable compounds shown in Figure 14 helps to observe that the first group of reactions mainly corresponds to reduction (elimination of oxygenated bonds and functions); the second includes a new elimination of oxygen and a disproportionation resulting in compounds richer in hydrogen (hydrocarbons for which $\mathrm{C} / \mathrm{H}$ is around 6 to 9) and more condensed compounds, poor in hydrogen.

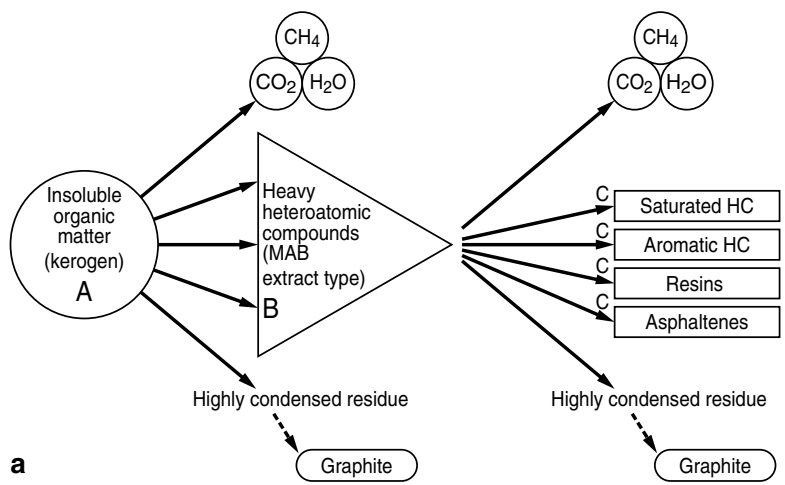

Figure 13a

Kerogen degradation flowsheet.

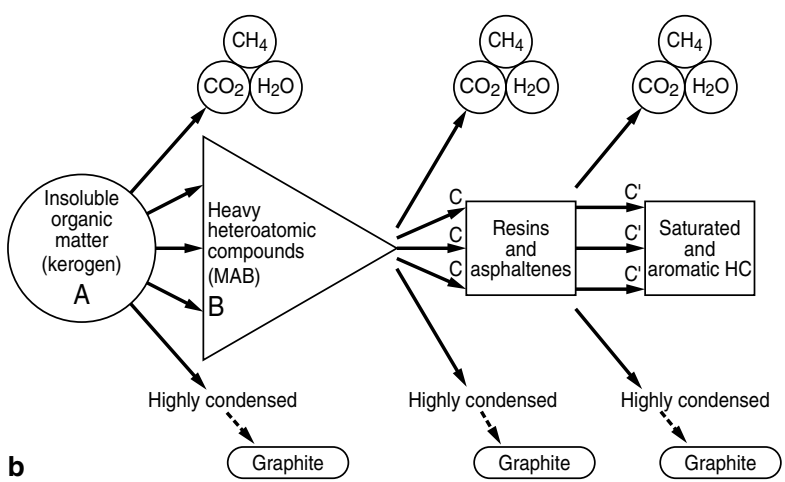

Figure 13b

Variant of above flowsheet.

Note that the highly condensed residues which evolve towards graphite cannot be separated from kerogen A with common fractionation methods.

\subsection{Remarks}

The reaction flowsheet proposed calls for the following remarks:

- The arrows actually represent a group of parallel or successive reactions whereof the intermediate steps are inaccessible to observation. A steady state is assumed to be established and these intermediates are ignored, just as only states with a long half-life are retained in the disintegration equations.

- An examination of Figures 5 and 14 indicates a variant of the previous reaction flowsheet: the resins and asphaltenes could represent an intermediate before culminating in hydrocarbons. This variant is shown in Figure 13b. It has not been used in the calculations in Chapter 4, to avoid needlessly complicating these calculations.

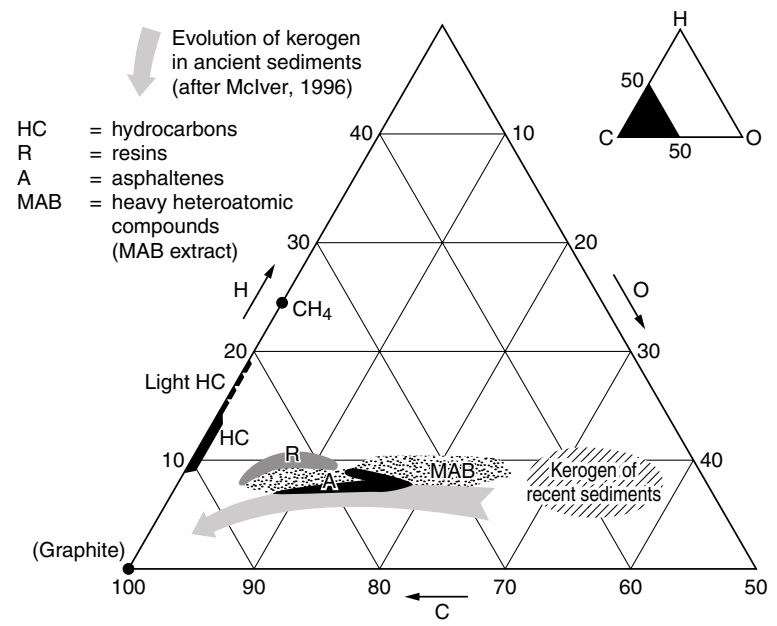

Figure 14

Elementary composition of the various organic components of sediments and evolution of kerogen.

- On the whole, the rest of the reactions cannot be expected to be reversible. If, for example, the system is raised to $80^{\circ} \mathrm{C}$, a part of the organic raw material is decomposed but, if we return to the temperature and pressure conditions of the superficial environment of the deposit (by erosion), the original organic matter is not reformed. Besides, the probably very abundant formation of $\mathrm{CO}_{2}$, $\mathrm{H}_{2} \mathrm{O}$, and $\mathrm{CH}_{4}$, which are more mobile and disappear, also makes the reactions irreversible.

- In natural conditions, most of the kerogen A remains in the macromolecular state and does not undergo the conversion $\mathrm{A} \rightarrow \mathrm{B}$. For example, in the case of the Toarcian in the Paris Basin, the organic carbon thus immobilized, depending on the temperatures reached, represents 0.85 to 0.95 of the total organic carbon. We know, however, that other bonds can be broken - and new extractable products formed-by raising the sediment to higher temperatures: 180 to $300^{\circ} \mathrm{C}$ in the laboratory experiments, up to $500^{\circ} \mathrm{C}$ in the oil shale industry. This accordingly leads to the concept of the distribution of activation energies for the elimination of the different 
functional bonds, a distribution such that, for each temperature range, a new category of bonds occurs, whereas those corresponding to the higher energies are practically untouched.

\section{EXPRESSION AND COMPUTER SIMULATION OF A KINETIC MODEL}

\subsection{Expression of Equations}

It would be misleading to try to monitor the transformations of one compound or another in detail to establish specific laws which govern an individual transformation. The construction of a kinetic model makes it possible to simulate the reaction flowsheet in Figure 13 on a computer, and thereby to analyze the functioning of the complex transformation.

One essential advantage of the model is the introduction of time and temperature, i.e. of the geological history of the sediment after its deposition. The model thereby helps to calculate, for a given formation and at each point of the basin, the result of the transformation of the organic matter as a function of its geological history. After having written it, we can therefore calculate the quantities of oil formed in the Toarcian in the Paris Basin up to the Present, at each point where samples are available (borehole); the necessary numerical constants are evaluated from the observations and/or adjusted by comparison with the observations and laboratory experiments. The consistency of the results obtained justifies the validity of the model for simulating natural phenomena.

We therefore start with the reaction flowsheet in Figure 13a, which is symbolized by:

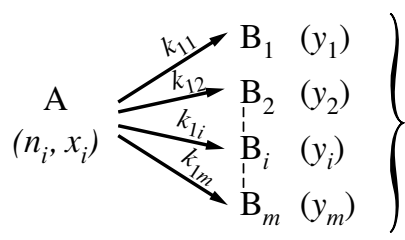

B

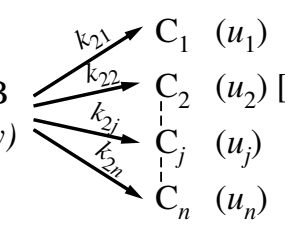

At time $t, n_{i}$ represents a number of bonds of a given type $i, x_{i}$, the quality of matter involved in the $i^{\text {th }}$ reaction (splitting of the $i$ bond), $y_{i}$ and $u_{j}$ the quantity of compounds $\mathrm{B}_{i}$ and $\mathrm{C}_{j}$. The quantities resulting from the observation of natural samples are $x$ (kerogen), $y$ (heavy heteroatomic compounds from MAB extract) and $u_{1}, u_{2}, \ldots$ (saturated aromatic hydrocarbons, resins, asphaltenes).

As stated earlier, the $\mathrm{A} \rightarrow \mathrm{B}$ group represents a set of parallel reactions (i.e. the probability of splitting of a given bond is independent of the presence of the other bonds) and/or successive. We assume that the probability of the splitting of a bond is independent of the time elapsed; the breakage of the bond accordingly obeys a Poisson's ratio, which is widely encountered in nature (radioactivity), i.e.:

$$
-\frac{\mathrm{d} n_{i}}{n_{i}}=k_{1 i} \mathrm{~d} t
$$

where $k$ is a constant at a given temperature.

If we assume that the density of the bonds is uniform throughout the volume (homogeneous structure), and if $P_{i}$ is the frequency of the $i$ bond in the original organic matter at time $t=0$, we have:

$$
\begin{array}{ll}
x_{i 0}=\mathrm{x}_{0} P_{i} & \text { (parallel reaction) } \\
x_{i}=\mu n_{\mathrm{i}} & \text { (homogeneous material) }
\end{array}
$$

we therefore obtain:

$$
-\frac{\mathrm{d} x_{i}}{\mathrm{~d} t}=k_{1 i} x_{i}
$$

the subscript 0 representing the quantity at time $t=0$ and $\mu$ being a constant.

For each of the $i$ reactions, we therefore obtain equations identical to those of the first order reactions. We also assume that the liberated structure of polymer $\mathrm{A}$ is independent of the nature of $i$. We can therefore consider $\mathrm{B}_{i}$ as statistically identical and for the second transformation only consider $\mathrm{B}=\sum_{i} \mathrm{~B}_{i}$. We can then similarly write, and for the same reasons, the differential equations of the $\mathrm{B} \rightarrow \mathrm{C}$ transformations.

The quantities $x_{i}$, and $u_{j}$ are then solutions of a system of first order differential equations with variable coefficients since the $k$ depend on the temperature, hence on time, via the subsidence:

$$
\left.\begin{array}{rl}
-\frac{\mathrm{d} x_{i}}{\mathrm{~d} t} & =k_{1 i} x_{i} \\
\frac{\mathrm{d} u_{j}}{\mathrm{~d} t} & =k_{2 j} y \\
y & =\sum_{i} y_{i} \\
\sum_{i} x_{i 0} & +\sum_{i} y_{i 0}+\sum_{j} u_{j 0}=\sum_{i} x_{i}+\sum_{i} y_{i}+\sum_{j} u_{j}
\end{array}\right\}
$$

It can be observed immediately that the differential equations of the system [II] are not integrable with the help of simple functions if we assume that $k$ vary with temperature $\theta$, hence with time $t$, according to a law like the Arrhenius' law. We therefore, first in Section 4.2, carry out the theoretical calculation of the transformation at constant temperature (for example the maximum temperature or the mean temperature), to have an idea of the general form of the results. We shall then examine, in Section 4.3, an actual case at constant subsidence. In fact, although the equations are not integrable, they can be simulated on a computer. 


\subsection{Theoretical Study of Transformation at Constant Temperature}

We shall only consider bonds of a single type $(i)$ of frequency $P_{i}=1$, and reactions $\mathrm{B} \rightarrow \mathrm{C}_{i}$ of two types:

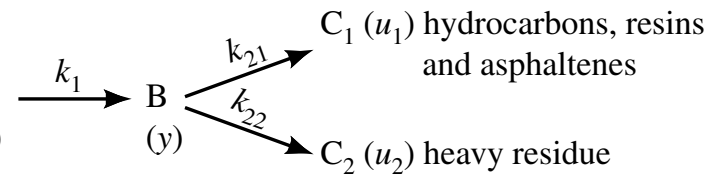

We also assume that the values of the origin $y_{0}, u_{10}, u_{20}$ are zero.

The calculation is performed in Appendix I. The following values are obtained for $y, u_{1}$ and $u_{2}$.

$$
\begin{gathered}
y=\frac{x_{0} k_{1}}{k_{1}-\left(k_{21}+k_{22}\right)}\left[e^{-\left(k_{21}+k_{22}\right) t}-e^{-k_{1} t}\right] \\
u_{1}=S \frac{k_{21}}{k_{21}+k_{22}} \quad u_{2}=S \frac{k_{22}}{k_{21}+k_{22}}
\end{gathered}
$$

by setting:

$$
S=u_{1}+u_{2}=x_{0}\left[1+\frac{\left(k_{21}+k_{22}\right) e^{-k_{1} t}-k_{1} e^{-\left(k_{21}+k_{22}\right) t}}{k_{1}-\left(k_{21}+k_{22}\right)}\right]
$$

The shape of the curves given $x, y, u_{1}, u_{2}$ as a function of $t$ is shown in Figure 15.

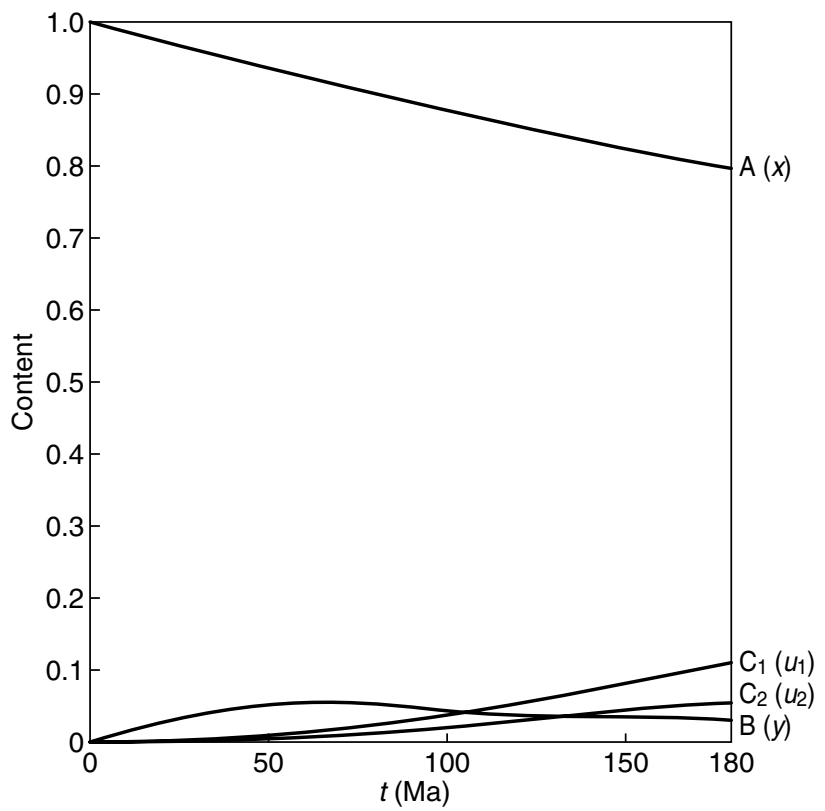

Figure 15

Example of evolution of contents as a function of time for a transformation at constant temperature.

\subsection{Computer Simulation of an Actual Case}

In the first step, we only considered two values of $i$ and two values of $j$. A second more complete version is being constructed.

The actual case of the burial of a sediment can be treated as a succession of periods in which the subsidence is constant. This is in fact the form in which the burial history is reconstructed by the geologist. During each period, the temperature is accordingly a linear function of time $T=\mu t+v$.

For the variation of $k_{1 i}$ and $k_{2 j}$ with temperature, we adopt a function of the Arrhenius' type:

$$
k_{1 i}=\mathrm{A}_{1 i} e^{-\frac{\mathrm{E}_{1 i}}{\mathrm{RT}}}
$$

In fact, the examination of natural phenomena (Figs. 7 and 8) implied that the degree of advancement of the reaction varies with temperature according to Arrehnius' law. Appendix II shows that this is effectively acceptable for a group of products, and that some of the $\mathrm{E}_{2 j}$ can be evaluated.

The integration of system [II] is no longer feasible using simple functions; a computer simulation was therefore carried out. In fact, a numerical integration by the finite differences method is possible, because the functions involved in [II] are continuous throughout as well as their primitives.

Let $\Delta t$ be the integration step. If $x_{i}, y_{i}, u_{i}$ are the values of the valuables at time $t$, they are $x_{i}+\Delta x_{i}, y_{i}+\Delta y_{i}, u_{j}+\Delta_{u j}$ in the following step $t+\Delta t$. By replacing $k_{1 i}$ by its value, from Equation (I) of the system [II], we obtain that $\Delta_{x i}$ from $x_{i}$ :

$$
\Delta x_{i}=-\mathrm{A}_{1 i} e^{-\frac{\mathrm{E}_{1 i}}{\mathrm{R}(\mu t+v)}} x_{i} \Delta t
$$

At time $t+\Delta t$, the value thus calculated for $x_{i}$ is $x_{i}+\Delta x_{i}$. If the concentrations $x_{i 0}$ at time 0 are known, we can therefore calculate the successive approximate values of $x_{i}$, as well as $x=\Sigma x_{i}$ by summating the results obtained for the $i$ equations, at each step.

From Equation (4), we obtain:

$$
y=x_{0}+y_{0}+u_{0}-\sum_{i} x_{i}-\sum_{j} u_{j} \quad \text { with: } x_{0}=\Sigma x_{i 0}, u_{0}=\Sigma_{j 0}
$$

By setting this result in (2), considering that the increase $\Delta t$ corresponds to the increase $\Delta u_{j}$ of $u_{j}$, and by replacing $k_{2 j}$ by its value, we obtain for the $j^{\text {th }}$ equation:

$$
\Delta u_{j}=\mathrm{A}_{2 j} e^{-\frac{\mathrm{E}_{2 j}}{\mathrm{R}(\mu t+v)}}\left(x_{0}+y_{0}+u_{0}-\sum_{i} x_{i}-\sum_{j} u_{j}\right) \Delta t
$$

If $x_{0}, y_{0}, u_{0}$, are known, the approximate values of $u_{j}$ can be calculated by successive steps by setting in (7) at each step 
$\sum_{j} u_{j}$ and $\sum_{i} x_{i}$ determined in the previous step; at time $t=0$, we give to $\Sigma x_{i}$ and $\Sigma u_{j}$ the values $x_{0}$ and $u_{0} ; y$ is simultaneously obtained using (6).

A discrete series of approximate values of $x_{i}, u_{j}$ and $y$ is therefore easily calculable as a function of time.

The difference between the curves thus constructed and the integral curves decreases as the time step $\Delta t$ is decreased. The approximation obtained is considered sufficient when, for two successive values of a step, the difference between the two calculated values of the same variable corresponding to the same time $t$ is lower than a fixed value (in the present case, a ratio of this difference to the calculated value of the variable less than $10^{-3}$ at the final time is adequate). The calculation shows that this condition is satisfied in most cases for a step of $0.25 \mathrm{Ma}$.

The $x_{0}, y_{0}, u_{0}$, as well as the $\mathrm{A}_{1 i}, \mathrm{E}_{1 i}, \mathrm{~A}_{2 j}$ and $\mathrm{E}_{2 j}$ are the free parameters of the system. The values at the origin of time are selected from the values observed in the present sediments, particularly those of the Black Sea where the depositional conditions appear similar (Gorskaya, in: Vassoevich, 1958). The $\mathrm{A}$ and $\mathrm{E}$ are determined in two steps. The order of magnitude of the $\mathrm{E}_{2 j}$ and $\mathrm{A}_{2 j}$ is derived from our own observations and experiments (Appendix II); the optimal adjustment is then carried out by iteration between the calculation results and the observed values.

The calculations presented below were performed using the following values ${ }^{1}$, and the time units are millions of years:

$$
\begin{array}{lll}
\mathrm{E}_{11}=2 \mathrm{kcal} / \mathrm{mol} & \mathrm{A}_{11}=1 & \\
\mathrm{E}_{12}=17 \mathrm{kcal} / \mathrm{mol} & \mathrm{A}_{12}=3 \cdot 10^{8} & \\
\mathrm{E}_{21}=15 \mathrm{kcal} / \mathrm{mol} & \mathrm{A}_{21}=10^{8} & \text { (HC + res. }+ \text { as. }) \\
\mathrm{E}_{22}=7 \mathrm{kcal} / \mathrm{mol} & \mathrm{A}_{22}=3.3 \cdot 10^{2} & \text { (heavy residue) }
\end{array}
$$

All the calculations were performed on a CDC 6400 computer.

\subsection{Results Obtained by Simulation of the Actual Case}

By way of example, Figure 16 shows the curve of the formation of petroleum components (hydrocarbons + resins + asphaltenes) from one gram of organic carbon, calculated by the model for the Lower Toarcian of the Essises well. The lower part of the figure shows the corresponding formation rate, also as a function of time, in millions of years. The angular shape of the rate curve is explained by that of the burial curve, hence of the temperature as a function of time.

(1) If the laboratory experiments at high temperature are also to be represented, it is necessary to introduce other higher values of $E_{1}$ : this yields a distribution of $E_{1 i}$ where the mean is about $30 \mathrm{kcal} / \mathrm{mol}$.
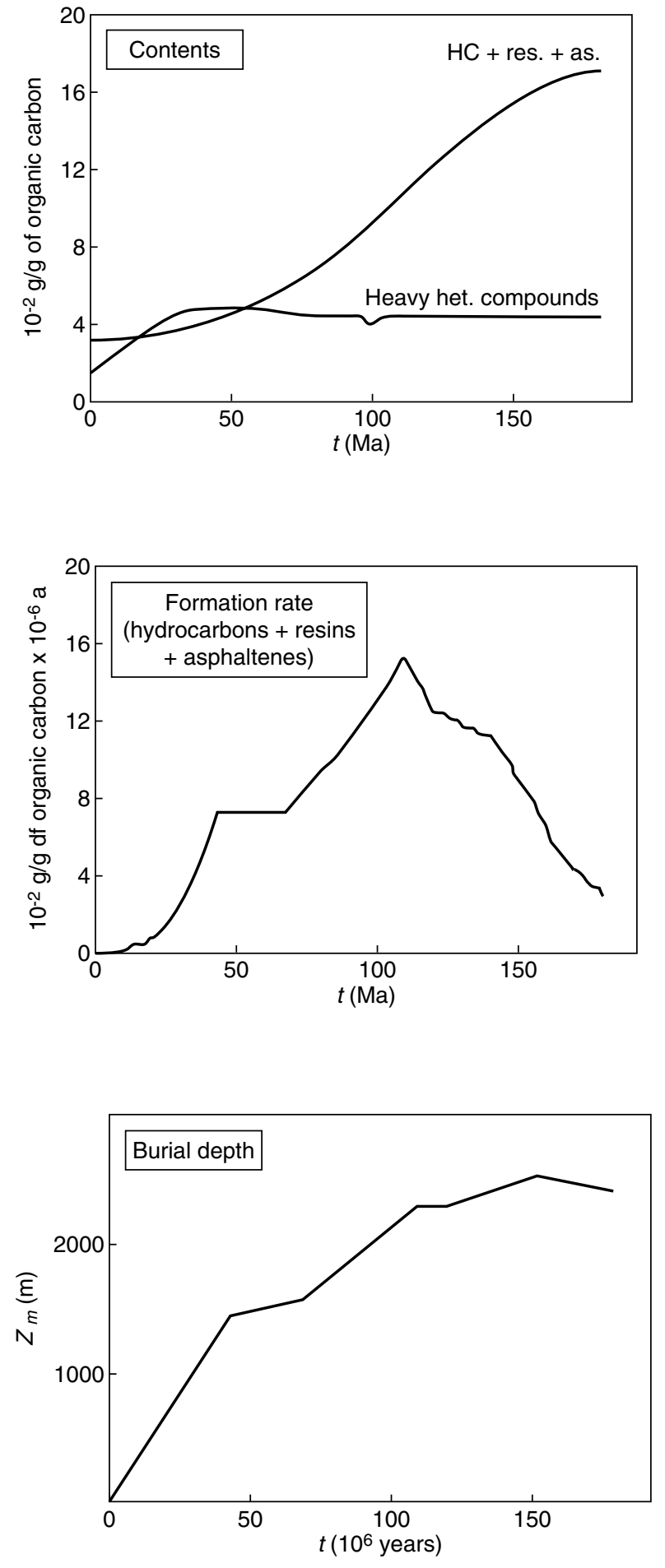

Figure 16

Content of petroleum compounds (hydrocarbons + resins + asphaltenes) in heavy heteroatomic compounds, and formation rate as a function of time for the Toarcian of the Essises well.

Given at the bottom is the burial curve reconstructed by the geologist, which serves to determine the temperature distribution as a function of time. 
The results for all the twenty-three wells show excellent agreement between the contents of the petroleum components thus calculated and those observed on the samples (Fig. 17). The correlation factor is 0.90 ; it reaches 0.96 if we ignore one of the wells whose behavior on natural samples appears to be anomalous with respect to its neighbors. The mean square error between calculated and observed values is about $10^{-2}$.

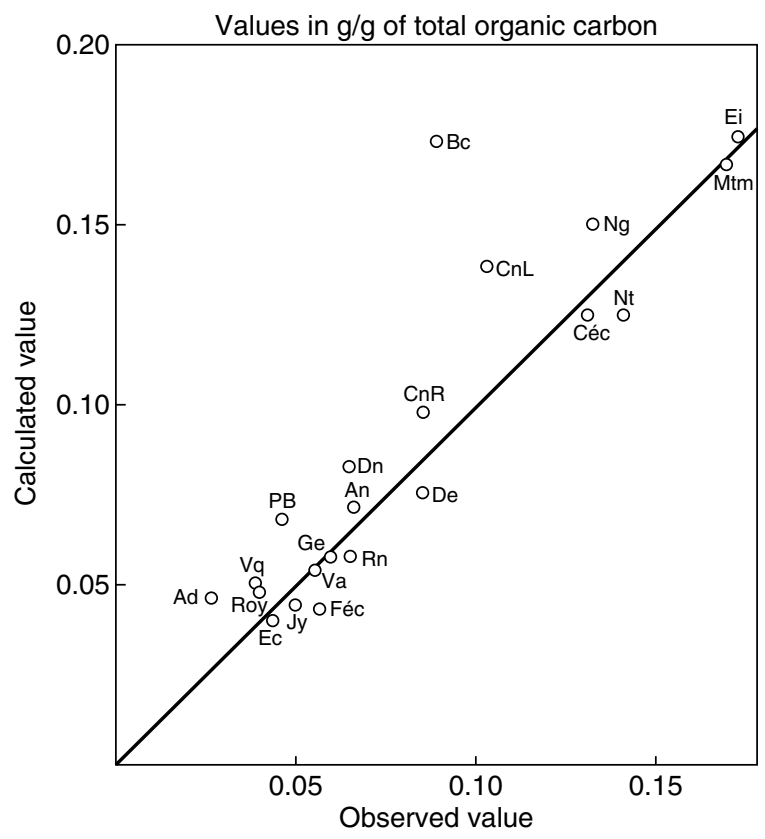

Figure 17

Correlations between quantities of hydrocarbons + resins + asphaltenes measured on the clay samples of the Toarcian in the Paris Basin, and the quantities calculated by computer simulation of the kinetic flowsheet.

\section{CONCLUSIONS}

Using the results of observations and experiments on the Toarcian in the Paris Basin, it was accordingly possible to construct a simplified reaction flowsheet, and then simulate the transformation on a computer. The consistency of the overall results shows that the reaction flowsheet and the kinetics implied are compatible with reality. We therefore have a model to represent the natural phenomena and contribute to their study.

The use of this tool helps explicitly to introduce the time and temperature parameters, i.e. the overall geological history of the sediment after its deposition, instead of only considering a specific episode (maximum burial depth or present depth). Besides, this makes it possible to separate the respective influence of time and temperature, which was not hitherto possible.

In terms of prospecting, this tool helps to simulate the quantities of oil formed at any point of the basin investigations, and with a good approximation, from the time of deposition to the present. We can thus determine the most favorable zones, i.e. those in which the source rock has been the most productive. It is obviously easy to take account of the organic matter contents and the thickness of the formation.

We can also consider extending this model to other formations, and then to other sedimentary basins, to contribute to prospecting. This aspect is the subject of another publication ${ }^{2}$. It suffices to have the measurements on a small number of core samples (to adjust the constants specific to the formation concerned), a reconstruction of the geological history of the basin, and an evaluation of the geothermal gradient.

Finally, the use of the model provides the first data, still approximate, on the timing and the formation rate of the oil; the comparison of these data with the age of the structural movements will perhaps make it possible, in some basins, to select the most favorable traps.

\section{REFERENCES}

Correia, M. (1967) Relations possibles entre l'état de conservation des éléments figurés de la matière organique (microfossiles palynoplanctologiques) et l'existence de gisements d'hydrocarbures. Rev. Inst. franç. du pétrole, 22, 9, 12851306.

Deroo, G., Durand, B., Espitalié, J., Pelet, R. and Tissot, B. (1968) Possibilités d'application des modèles mathématiques de formation du pétrole à la prospection dans les bassins sédimentaires. 4th International Meeting on Organic Geochemistry, Amsterdam, Sept. 1968.

Erdman, J.G. (1965) The Molecular Complex Comprising Heavy Molecular Fractions. Hydrocarbon Analysis, ASTM, STP, 389.

Long, G., Neglia, S. and Favretto, L. (1968) The Metamorphism of the Kerogen from Triassic Black Shales, Southeast Sicily. Geochim. et Cosmochim. Acta, 32, 647-656.

Louis, M. (1964) Études géochimiques sur les «Schistes cartons» du Toarcien du Bassin de Paris. In: Advances in Organic Geochemistry, G.D. Hobson et M.C. Louis (eds), Pergamon Press, Oxford, 85-94.

Louis, M. and Tissot, B. (1967) Influence de la température et de la pression sur la formation des hydrocarbures dans les argiles à kérogène. 7th World Petrol. Congress, Mexico, 2, 47-60.

McIver, R.D. (1967) Composition of Kerogen. Clue to its Role in the Origin of Petroleum. 7th World Petrol. Congress, Mexico, 2, 25-36.

(2) Deroo, G., Durand, B, Espitalié, J., Pelet, R and Tissot, B (1968) Possibility of Application of Mathematical Models of Petroleum Formation in Prospecting in Sedimentary Basins. 4th International Meeting on Organic Geochemistry, Amsterdam, Sept. 1968. 
Philippi, G.T. (1965) On the Depth, Time and Mechanism of Petroleum Generation. Geochim. et Cosmochim. Acta, 29, 10211049.

Tissot, B. (1966) Problèmes géochimiques de la genèse et de la migration du pétrole. Rev. Inst. franç. du pétrole, 21, 2, 1621-1671.

Vassoevich, N.B. (1958) Problèmes de la formation du pétrole. (En russe) Trudy VNIGRI, Public., 128, Gostoptekhizdat.

Vassoevich, N.B., Visotski, I.V., Guseva, A.N. et Olenin, V.B. (1967) Hydrocarbons in the Sedimentary Mantle of the Earth. 7 th World Petrol. Congress, Mexico, 2, 37-45.
Welte, D.H. (1966) Kohlenwasserstoffgenese in Sedimentgesteinen : Unterserchungen über den thermischen Abbau von Kerogen unter besonderer Berücksichtigung der $n$-Paraffinbildung. Geol. Rundschau, 55-I, 131-144.

Paper translated from Tissot, B. (1969) "Premières données sur les mécanismes et la cinétique de la formation du pétrole dans les sédiments. Simulation d' un schéma réactionnel sur ordinateur», Revue de l'Institut français du pétrole, 24, 4, 470-501. 


\section{APPENDIX I}

\section{THEORETICAL STUDY OF TRANSFORMATION AT CONSTANT TEMPERATURE}

We consider the flowsheet:

A

$(x)$

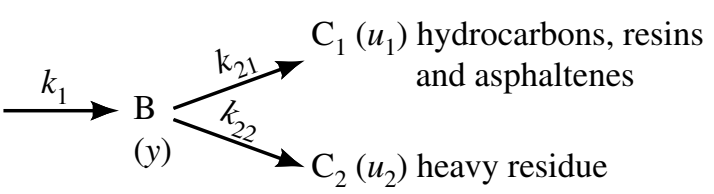

In system [II], we accordingly have a single value of $i$ with $P_{i}=1$ and two values of $j: 1$ and 2. $y_{0}, u_{10}, u_{20}$ are zero.

The system becomes:

$$
\begin{aligned}
& -\frac{\mathrm{d} x}{\mathrm{~d} t}=k_{1} x \\
& \frac{\mathrm{d} u_{1}}{\mathrm{~d} t}=k_{21} y \\
& \frac{\mathrm{d} u_{2}}{\mathrm{~d} t}=k_{22} y \\
& x_{0}=x+y+u_{1}+u_{2}
\end{aligned}
$$

Setting $S=u_{1}+u_{2}$; we obtain:

$$
\begin{aligned}
x & =x_{0} e^{-k_{1} t} \\
\frac{\mathrm{d} s}{\mathrm{~d} t} & =\left(k_{21}+k_{22}\right) y=\left(k_{21}+k_{22}\right)\left(x_{0}-x-s\right) \\
\frac{\mathrm{d} s}{\mathrm{~d} t} & =\left(k_{21}+k_{22}\right) S=\left(k_{21}+k_{22}\right) x_{0}\left(1-e^{-k_{1} t}\right)
\end{aligned}
$$

By integrating the equation without a second member, we have:

$$
\begin{aligned}
S & =M \cdot e^{-\left(k_{21}+k_{22}\right) t} \\
\frac{\mathrm{d} s}{\mathrm{~d} t} & =e^{-\left(k_{21}+k_{22}\right) t}\left[\frac{\mathrm{d} M}{\mathrm{~d} t}-M\left(k_{21}+k_{22}\right)\right]
\end{aligned}
$$

Let us set in the complete differential equation:

$$
\frac{\mathrm{d} M}{\mathrm{~d} t} e^{-\left(k_{21}+k_{22}\right) t}=\left(k_{21}+k_{22}\right) x_{0}\left(1-e^{-k_{1} t}\right)
$$

$$
\begin{gathered}
\frac{\mathrm{d} M}{\mathrm{~d} t}=\left(k_{21}+k_{22}\right) x_{0}\left[e^{\left(k_{21}+k_{22}\right) t}-e^{-\left(k_{1}-k_{21}-k_{22}\right) t}\right] \\
M=x_{0} e^{\left(k_{21}+k_{22}\right) t}\left[1+\frac{k_{21}+k_{22}}{k_{1}-k_{21}-k_{22}} e^{-k_{1} t}+\mathrm{Cte} \cdot e^{-\left(k_{21}+k_{22}\right) t}\right] \\
S=x_{0}\left[1+\frac{k_{21}+k_{22}}{k_{1}-k_{21}-k_{22}} e^{-k_{1} t}+\mathrm{Cte} \cdot e^{-\left(k_{21}+k_{22}\right) t}\right]
\end{gathered}
$$

In fact, for $t=0, s=0$, hence:

$$
\mathrm{Cte}=-\frac{k_{1}}{k_{1}-\left(k_{21}+k_{22}\right)}
$$

This gives:

$$
S=x_{0}\left[1+\frac{\left(k_{21}+k_{22}\right) e^{-k_{1} t}-k_{1} e^{-\left(k_{21}+k_{22}\right) t}}{k_{1}-\left(k_{21}+k_{22}\right)}\right]
$$

and since:

$$
\frac{u_{1}}{u_{2}}=\frac{k_{21}}{k_{22}}
$$

$$
\begin{gathered}
u_{1}=S \frac{k_{21}}{k_{21}+k_{22}} \quad u_{2}=S \frac{k_{22}}{k_{21}+k_{22}} \\
y=\frac{x_{0} k_{1}}{k_{1}-\left(k_{21}+k_{22}\right)}\left[e^{-\left(k_{21}+k_{22}\right) t}-e^{-k_{1} t}\right]
\end{gathered}
$$




\section{APPENDIX II}

\section{ANALYSIS OF TRANSFORMATION RATES EVALUATION OF PSEUDO-ACTIVATION ENERGIES}

1) We consider here the formation of compounds of petroleum $\mathrm{C}$ in transformations at constant subsidence $\lambda$, i.e. where the temperature $\theta$ is a linear function of time $t$. In the beginning (Fig. 4), when $t$ and $\theta$ are low, reaction $\mathrm{A} \rightarrow \mathrm{B}$ practically does not occur and everything takes place as if $\mathrm{C}$ was formed from reactant $\mathrm{B}$ available in quantity $y$ at the start of the reaction. We can therefore try to evaluate the constants of reaction $\mathrm{B} \rightarrow \mathrm{C}$. This is no longer valid beyond about $60^{\circ} \mathrm{C}$, since reaction $\mathrm{A} \rightarrow \mathrm{B}$ occurs and therefore modifies the concentration and rates.

2) If we consider the rates $V=\left(\frac{\mathrm{d} u}{\mathrm{~d} t}\right)_{\lambda}$ (calculated in Section 2.3 from the rates observed $\left(\frac{\mathrm{d} u}{\mathrm{~d} z}\right)_{\lambda}$, we find in Figure 18 that $\log 1 / y V_{\lambda}$ varies more or less linearly with $1 / T$ at moderate temperatures (up to about $60^{\circ} \mathrm{C}$ ). The alignment is good and encourages seeking an interpretation with an Arrhenius' type equation. We shall do this by introducing various assumptions, but we first face two difficulties:

a) the rate observed concerns a set of reaction products, characterized either by a property (solubility in $\mathrm{CHCl}_{3}$ ), or by their structure (hydrocarbons), to the exclusion of the other reaction products;

b) kinetic interpretations classically use the relation between the formation rate $V_{\theta}$ (at constant temperature) and $1 / T$; it is therefore necessary to analyze the relation between $V_{\lambda}$ (at constant subsidence) and $V_{\theta}$; these two points are considered in 3 ) and 4).

3) We consider a system in which a reactant B is converted into a large number $n$ of compounds $\mathrm{C}$ (miscellaneous hydrocarbons, resins, asphaltenes):

$$
\beta \mathrm{B} \rightarrow \gamma_{1} \mathrm{C}_{1}+\gamma_{2} \mathrm{C}_{2}+\gamma_{3} \mathrm{C}_{3}+\ldots \gamma_{n} \mathrm{C}_{n}
$$

where $y$ and $u_{i}$ represent the quantity of $\mathrm{B}$ and $\mathrm{C}_{i}$.

If the nature of the reaction does not change in the temperature range considered we have:

$$
-\mathrm{d} y=\frac{\beta^{\prime}}{\gamma_{1}^{\prime}} \mathrm{d} u_{1}=\frac{\beta^{\prime}}{\gamma_{2}^{\prime}} \mathrm{d} u_{2}=\ldots=\frac{\beta^{\prime} \sum_{i}^{p} \mathrm{~d} u_{i}}{\sum_{i}^{p} \gamma^{\prime} i}
$$

where $\beta^{\prime}$ and $\gamma_{i}^{\prime}$ represent the masses of $\beta$ molecules $\mathrm{B}, \gamma_{i}$, molecules $\mathrm{C}_{i}$, etc.

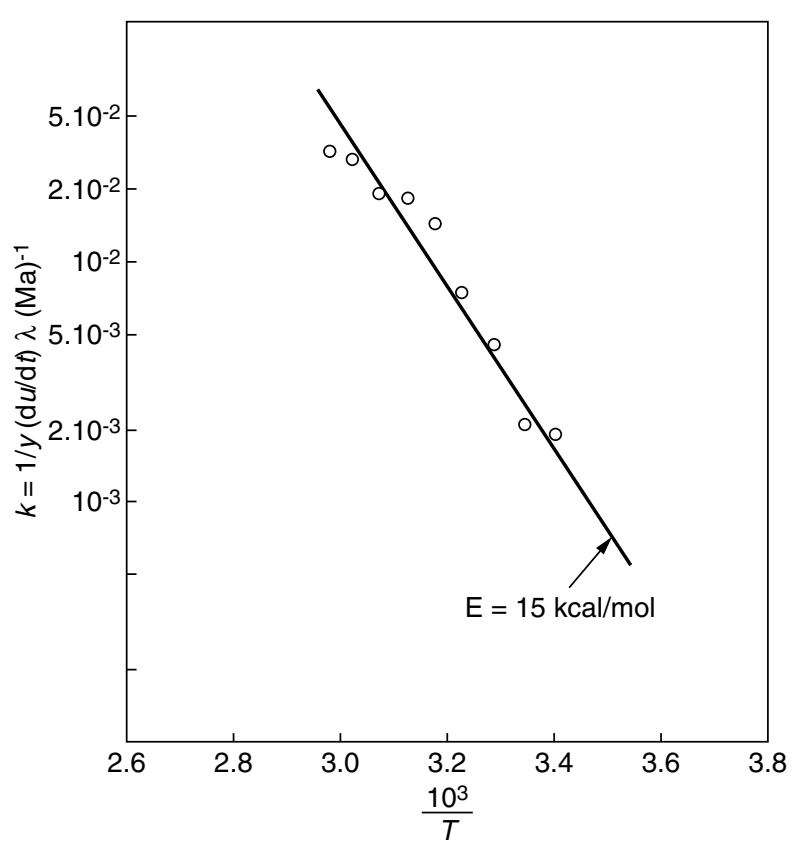

Figure 18

Relation between rate constant and temperature for the formation of petroleum compounds.

Hence if $u=\sum_{i}^{p}$ is the sum of a set of small $p$ components, with $p \leq n$, we have:

$$
-\mathrm{d} y=\xi \mathrm{d} u
$$

where $\xi$ is a constant that only depends on the type of reaction.

In the present case, we denote by $u$ all the hydrocarbons, resins and asphaltenes, extractable by common solvent (chloroform) knowing that $n-p$ components remain, which are not extractable, or disappear (such as $\mathrm{CO}_{2}$ entrained by water and light hydrocarbons lost during extraction). The reaction rate is therefore:

$$
-\frac{\mathrm{d} y}{\mathrm{~d} t}=+\xi \frac{\mathrm{d} u}{\mathrm{~d} t}
$$

4) If, as in Section 2.3, we consider the general equation:

$$
\mathrm{d} u=\left(\frac{\partial u}{\partial t}\right)_{\theta} \mathrm{d} t+\left(\frac{\partial u}{\partial \theta}\right)_{t} \mathrm{~d} \theta
$$

it becomes in a transformation at constant subsidence:

$$
\left(\frac{\mathrm{d} u}{\mathrm{~d} t}\right)_{\lambda}=\left(\frac{\partial u}{\partial t}\right)_{\theta}+\lambda G\left(\frac{\partial u}{\partial \theta}\right)_{t} \quad V_{\lambda}=V^{\theta}+\lambda G\left(\frac{\partial u}{\partial \theta}\right)_{t}
$$

Even in the case of the simple system that we have considered, the calculation of the difference $V_{\lambda}-V_{\theta}$ cannot be made accurately. However, we can calculate $V_{\lambda}$ 
and $V_{\theta}$ using the model constructed on a computer and which is presented above. We therefore see that in the range of transformations considered, this difference can be ignored (less than 10\%) of the $V_{\lambda}$ ). This is not surprising, since the temperature rises about a half a degree per million years.

5) To analyze the variation in the rate constant $k$ of reaction $\mathrm{B} \rightarrow \mathrm{C}$, we have plotted in Figure 18, $\log k=\log \left(\frac{1}{y} \frac{\mathrm{d} u}{\mathrm{~d} t}\right)$ as a function of $1 / T$ in the interval limited to $60^{\circ} \mathrm{C}$.

The agreement observed with a linear distribution in $1 / T$ shows that an Arrhenius' type law is acceptable, and helps to calculate a pseudo-activation energy $\mathrm{E}$ (for the total reaction considered, with all the reservations this implies, but not for an individual reaction of the formation of a compound). The table below shows the pseudo-activation energies for a set of compounds $\mathrm{C}$, and for the various families they contain:

Formation of $\mathrm{C}$ $15000 \mathrm{cal} / \mathrm{mol}$

(hydrocarbons + resins + asphaltenes)

Formation of hydrocarbons

$20000 \mathrm{cal} / \mathrm{mol}$

Formation of resins and asphaltenes

6) We observe that the pseudo-activation energy for hydrocarbons is higher than that for all petroleum compounds, and in particular than that of resins and asphaltenes. This hence implies that the more the temperature increases, hence the burial, the more the hydrocarbons (particularly saturated hydrocarbons) are favored over the heavy products.

In the case of the Toarcian in the Paris Basin, Figure 4 shows that this is certainly the case since the percentage of hydrocarbons in the transformation products increases with depth. This is not an ordinary observation from early results since the absolute quantities of the different

components per $g$ of organic carbon all increase in the same way. At the world scale, we know that shallow oil reservoirs are statistically heavier and richer in resins than asphaltenes.

If, to simplify, we consider two twin reactions:

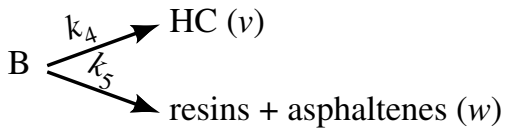

and if the reactions are of the same order, we have:

$$
\frac{\mathrm{d} v}{\mathrm{~d} w}=\frac{k_{4}}{k_{5}}
$$

If we assume as a first approximation that the transformation occurs at constant temperature (for example the maximum temperature or the mean temperature), we have at any time:

$$
\frac{v}{w}=\frac{k_{4}}{k_{5}}
$$

In fact:

$$
\log \frac{k_{4}}{k_{5}}=\log \mathrm{C}-\frac{\mathrm{E}_{4}-\mathrm{E}_{5}}{\mathrm{RT}}
$$

where $\log \mathrm{C}$ is a constant. Using the above values (20 and $14 \mathrm{kcal} / \mathrm{mol}$ for $\mathrm{E}_{4}$ and $\mathrm{E}_{5}$, we obtain:

$$
\log _{10} \frac{k_{4}}{k_{5}}=\log _{10} \mathrm{C}-\frac{6}{4.57} \cdot \frac{10^{3}}{T}=\log _{10} \mathrm{C}-1.3 \cdot \frac{10^{3}}{T}
$$

The graph giving $\log v / w$ as a function of $1 / T$ (Fig. 8) for the Toarcian samples, and the line with slope $1.3 \cdot 10^{3}$, shows that a law of this type fairly accurately represents the real mean distribution, although the differences are sometimes significant. 